\title{
Producing and Editing Diagrams Using Co-Speech Gesture: Spatializing Nonspatial Relations in Explanations of Kinship in Laos
}

\author{
Web-enhanced article
}

Additional materials related to this article are available at the JLA website: http://www.aaanet.org/sla/jlamain.htm, under the link "Web-enhanced articles."

This article presents a description of two sequences of talk by urban speakers of Lao (a southwestern Tai language spoken in Laos) in which co-speech gesture plays a central role in explanations of kinship relations and terminology. The speakers spontaneously use hand gestures and gaze to spatially diagram relationships that have no inherent spatial structure. The descriptive sections of the article are prefaced by a discussion of the semiotic complexity of illustrative gestures and gesture diagrams. Gestured signals feature iconic, indexical, and symbolic components, usually in combination, as well as using motion and three-dimensional space to convey meaning. Such diagrams show temporal persistence and structural integrity despite having been projected in midair by evanescent signals (i.e., hand movements and directed gaze). Speakers sometimes need or want to revise these spatial representations without destroying their structural integrity. The need to "edit" gesture diagrams involves such techniques as hold-and-drag, hold-and-work-with-free-hand, reassignment-of-old-chwonk-tonew-chunk, and move-body-into-new-space. 
7 his article describes two examples of the integration of speech and gesture in face-to-face interaction, from videotaped interviews concerning the kinL ship system and terminology of Lao speakers. ${ }^{1}$ The speakers in these two examples describe complex sets of relations among several different hypothetical kinsfolk, and in doing so they accompany their verbal explanations with highly structured series of manual gestures that complement the semantic content of their speech by establishing virtual diagrams in the immediate interactional space. These diagrams have special semiotic properties, lacking physical existence and yet remarkably showing temporal persistence and structural cohesion. The examples illustrate three points of importance concerning the encoding and communication of meaning in face-to-face interaction. The main contribution of the data presented here concerns the special semiotic properties of diagrams that speakers construct using gesture. These diagrams not only display spatial integrity and temporal persistence but also may be adjusted, revised, or edited online, as the need arises. Second, these data show that speakers do not rely on speech alone but draw on a range of semiotic resources to construct composite messages, distributing meaning across modalities (cf. Clark 1996; Engle 1998; Goodwin 2000; Kendon 1972; Slama-Cazacu 1976; inter alia). Third, speakers use the three-dimensional space within manual reach for spatial representation not only of spatial information but also of inherently nonspatial information through metaphorical mapping (cf. Emmorey 2001; McNeill 1992; inter alia).

An overarching issue concerns the status of the sharp line habitually drawn between speech and gesture. Co-speech gesture is a fundamental component of the semiotic repertoire of speakers, closely aligned with the meaning, structure, and production of speech (Kendon 1972, 1980; McNeill 1985, 1992, 2000). Can co-speech gesture be regarded as a mere add-on to an encapsulated system of speech? Or does speechwith-gesture constitute a coherent multimodal whole, such that to study one without the other (as linguistics almost exclusively does) is to misrepresent the fundamental nature of what it is that people do when they talk to each other? My position, following Kendon, is that the "theory of utterance ... should not begin with a division between 'speech' and 'gesture' and assume that these are quite different from one another" (1986:25).

The article begins with a discussion of semiotic properties of gestures and gesture diagrams. Then, after some preliminaries on the data collection and the general issue of Lao kinship, two examples are described in detail. The article concludes with a summary and discussion of issues arising from the data, including consideration of previous observations about spatial diagramming in sign language.

\section{Semiotic Properties of Co-Speech Gestures (and Manual Signs)}

Co-speech gesture refers to the communicative and informative movements people make with their hands, eyes, face, and body as they speak (Efron 1972; Ekman and Friesen 1969; Kendon 1972, 1980; McNeill 1985, 1992, 2000). There have been a number of different taxonomies of types of co-speech gesture (see discussion and references in McNeill 1992:75-77), including such categories as illustrators, regulators, adaptors, emblems, beats, iconics, metaphorics, pictographs, kinetographs, and deictic gestures. In this article, I consider a subset of these previously identified gesture types, namely those actions that can be uncontroversially regarded as intentionally 
performed by a speaker for the purpose of creatively conveying some aspect of what he or she is trying to say. Such gestures become especially important when a speaker finds words failing: Consider the difficulty of giving an accurate description, without using gesture (e.g., while talking on the telephone), of a complex mechanical device such as an animal trap or a structured spatial layout like a three-bedroom, split-level apartment.

Speakers can use their hands to create illustrations in the physical space before them, either as two-dimensional maps or diagrams, as if writing on an invisible board, or as three-dimensional models, as if sculpting with invisible clay (Emmorey et al. 2000). Such illustrations are routinely produced and comprehended, but when we consider closely their semiotic nature they appear almost miraculous. A speaker does not literally create an image of a spiral staircase when he makes circling-rising-lowering motions with his hands in the space before him. Unlike drawing with pen on paper, gesticulation does not normally leave an artifactual trace representing (iconically or otherwise) a referent or some part of it (but cf. Goodwin 2003). I assume that signification involves some artifactual signifier that stands for something (Peirce 1965:135). Since something stands for something else only by being interpreted by someone as doing so, we can regard a signified not as a property of a sign but as fundamentally nothing more than a "cognition of the mind" (Peirce 1965:142). Further, in some cases - for example, in some uses of gesture and sign language-a signifying structure, too, can be imagined and merely projected onto conceived discontinuities in the world.

A pen-and-paper diagram, such as a sketched street map, is an iconic representation of a physical referent, or something associated with that referent (e.g., its outline). Although the representational nature of ink on the page is not inherent-it only stands for something as long as a person regards it as doing so-its semiotic potential nevertheless persists in time. We can examine the pen-on-paper trace and declare that it is indeed an iconic representation if we judge that it physically resembles some representative feature of the referent. However, in the case of a co-speech gesture, the signifier often has no direct physical resemblance to any feature of the referent itself. Suppose that in using the word beach ball I make a two-handed gesture in front of my chest as if I were holding a beach ball. The gesture is not iconic of a beach ball, but rather of what hands would look like if they were holding a beach ball, and this metonymically (i.e., by association) evokes the idea of a beach ball. Metonymic reference is common in language and other semiotic systems, but what is of interest here is that with gestures such as the beach ball just described, the basic signifier-signified connection-hands held in a certain way standing for hands holding something of a certain shape-is transient, yet the signification may be transferred temporarily onto the chunk of space in which the gesture was performed. Even though I may go on to do something new with my hands, we may still imagine that the beach ball just referred to remains there (as is especially likely if I maintain my gaze on the chunk of space where the beach ball was just signified). This is semiotically different from a real pen-and-paper diagram. The signifying structure (the twohanded holding gesture) has vanished, but the signified idea (the beach ball) still has an extensional counterpart (i.e., a certain fixed chunk of space). A gesture can leave a trace with stable spatial coordinates, and this trace can be physically pointed to with a subsequent gesture. Spoken words, meanwhile, disappear into thin air. ${ }^{2}$ When gestures are used to draw or mold in space, interlocutors can and do act as if artifactual 
representations had been created in the physical space before them, despite their being drawn with invisible ink or sculpted from invisible clay.

We now consider in more detail how this process works.

\section{Indexicality and Iconicity}

Two important properties of gestures are indexicality and iconicity (Peirce 1965). These are not different kinds of signs or gestures, but different semiotic functions, which may be, and often are, combined in a single sign or gesture. An indexical relation is one of association or dynamical connection, as when smoke tells an observer there is fire or when a man's slurred voice reveals his drunken state. A linguistic example is the word wheels in John bought new wheels, which refers, by association, to a whole car. An iconic relation is one of likeness, as when a cloud reminds an observer of a giraffe because it has a similar shape. A linguistic example is John is a beanpole, suggesting likeness between John and a beanpole. However, the two linguistic examples just given primarily involve conventionalized symbolic associations, since the association of their signifying forms with their meanings is due not to likeness or association but to a law of social agreement. Another sense in which the linguistic examples are conventional is that the particular extension made (e.g., from wheels to "car") is only one of many conceivable ones. Thus, although a glove box is also part of a car, one could not convey the idea that John bought a new car by saying John bought a new glove box. Similarly, beanpole can be used to describe someone who is skinny like a beanpole, but not to describe something that is made of wood, even though the wooden thing is also like a beanpole.

\section{The Base/Referent Distinction}

A typical way in which iconicity and indexicality may be combined in a single sign is through deferred reference (Quine 1971:149), by which there is a motivated relation firstly between a signifier and some base (by iconic or other motivated means), and secondly from the base to the intended referent (Cohen et al. 1977:20-22). For example, the lexical sign meaning 'old' in American Sign Language is performed "by pulling the fist down from the chin (as if stroking one's beard)" (Mandel 1977:63). ${ }^{3}$ In this way, the sign is not directly iconic of the concept "old" but, rather, iconically denotes a base notion "beard," which in turn indexes (or points metonymically to) the concept actually being expressed, namely advanced age. ${ }^{4}$ Figure 1 shows a few examples, the first two from American Sign Language:

\begin{tabular}{ccccc}
\hline signifier & $>$ & base & $>$ & referent \\
fist pulled down from chin & $>$ & stroking beard & $>$ & 'ald' \\
hands tracing shape of a tube & $>$ tube in which diplom is presentod $>$ & 'diplom' \\
index finger oriented to chais & $>$ chair in which John was juat siting & $>$ & 'John' \\
\hline
\end{tabular}


The connection between signifier and base may be iconic, even to the extent of being predictable, but the link between base and referent is more often conventional while often being to some extent motivated. The signifier-base-referent device is important for understanding many examples of signification via co-speech gesture. We now consider a range of techniques for creating motivated reference (i.e., from signifier to base) using co-speech gestures and manual signs.

\section{A Taxonomy of Manual Sign Functions}

There are many ways in which the hands can convey information. Mandel (1977) catalogs a number of these, and his ideas are partially revised and elaborated later by Kendon (1988). ${ }^{5}$ In this section, I first sketch their analyses, along with a more recent taxonomy of semiotic devices used in co-speech gesture (Müller 1998). I then present my own taxonomy, incorporating, adapting, and expanding on some ideas from these earlier works.

Mandel distinguishes first between presentation and depiction. In presentation, the signer presents to the addressee "a token of the base object or of the body activity involved in the base action" (1977:64), either by mime of some action (e.g., grinding coffee as a base for the referent coffee) or by overt indexical reference to a thing (e.g., pointing to a body part when referring to that body part). In depiction, signers make a picture of the base or referent concept. Mandel distinguishes here between virtual and substitutive depiction (1977:65). In virtual depiction, "the signer pretends that his articulator (i.e., hand, finger, arm) leaves a trace as it moves, and he draws the picture with this imaginary trace" (Mandel 1977:65). (Imagine a speaker referring to the letter $X$, while drawing it in midair with his or her finger.) Mandel calls this sketching, as opposed to another rarer type of virtual depiction termed stamping, in which the hand "moves forward and then returns, like a rubber stamp, leaving its trace at the place where it stopped rather than along its course" (1977:67). In substitutive depiction, "the signer's articulator actually becomes the picture: a tree standing in the ground with its leaves fluttering, a bird's beak opening and closing, and an airplane flying" (Mandel 1977:65). Figure 2 summarizes Mandel's (1977) taxonomy.

Kendon (1988) presents a modified and expanded version of Mandel's taxonomy. Two higher-level categories, subsumed by Mandel's concept of presentation, are presenting and pointing. Kendon opposes these to characterizing signs, with three subcategories: sketching - in which "the hand is moved through space in such a way as to suggest the outline of something" (1988:175); modeling - in which the hand

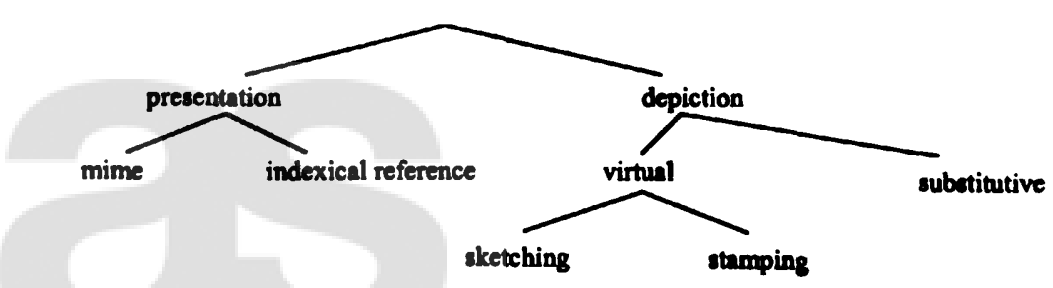




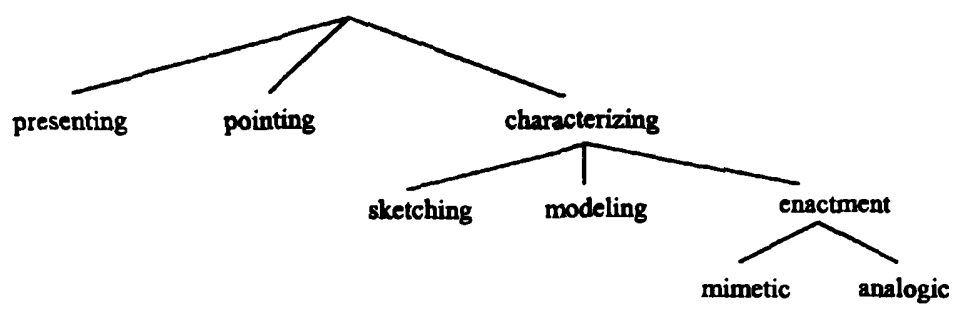

Figure 3

Semiotic devices of manual signs/gestures, according to Kendon (1988).

"is arranged in a pose that suggests a feature of the shape of an object which serves as the sign's base" (1988:173); and enactment-"in which a pattern of action is characterized" (1988:176). Two types of enactment are distinguished: mimetic enactment in which "patterns of manual action that an individual might actually engage in serve as the base" (1988:176 - cf. Mandel's example of the action of grinding coffee) and analogic enactment in which the movement of the hand "serves to present a movement ... analogous to a movement pattern that is in some way related to the referent" (1988:176) (e.g., a hand showing the curve of a bird's flight, but not depicting in any way the shape of the bird itself). Figure 3 summarizes Kendon's (1988) taxonomy.

More recently, Müller (1998) has sketched a simpler taxonomy of gesture/sign devices, concentrating not on sign language, but on co-speech gesture. She distinguishes "four basic modes of representation": "the hands imitate" (akin to Mandel's "presentation" or Kendon's "enactment"); "the hands draw" (corresponding to Mandel's "sketching"); "the hands portray" (akin to Mandel's "substitutive depiction" or Kendon's "modeling"); and "the hands mold" (Müller 1998:323). I suggest that this final category can be regarded as a subtype of the "the hands imitate," since it is not real molding of an object (nothing is touched or produced) but imitation of molding, holding, feeling the outlines of, or otherwise manipulating an object.

In Figure 4, I offer a taxonomy of the semiotic devices that can be identified in a subclass of co-speech gestures that we may roughly refer to as illustrative (i.e., not including beats, emblems, adaptors, or regulators; Ekman and Friesen 1969; McNeill 1992). This scheme adopts and adapts some of the insights of Mandel (1977), Kendon (1988), and Müller (1998). The major difference between Figure 4 and the previous two is that I have tried to base the grouping of subtypes on distinctions in the Peircean semiotic function(s) involved, resulting in some cases in different subgrouping of certain previously established categories. ${ }^{6}$ For instance, Kendon (1988) groups his "mimetic enactment" and "analogic enactment" together, based on the formal fact that they involve movement of the hands. Here, however, I keep them apart, since they exploit distinct semiotic devices. Mimetic enactment involves indexicality, since the hands do not look like the base, but rather look as if they were interacting with the base, whereas analogic enactment involves iconicity, since the movement of the hands themselves looks like movement of the thing signified. In terms of the semiotic devices employed, mimetic enactment may be grouped with virtual holding, since both involve indexical reference to the base via iconic representation of some inveraction 


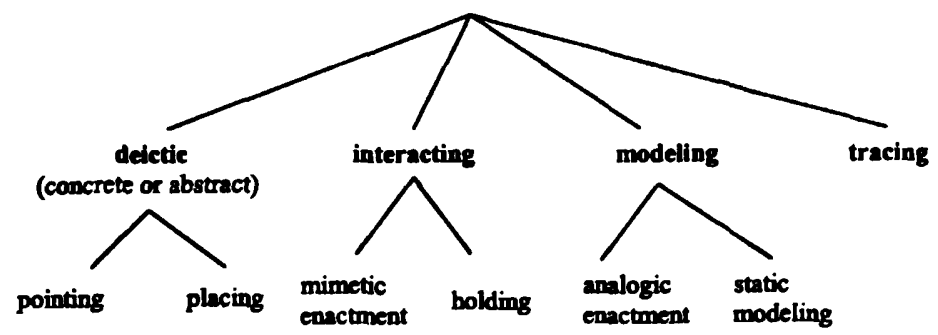

Deictie:

- semiotic function: indexical (in that the directional orientation of the gesture is determined by the conceived location of a base referent); the hands are used to bring the base and the attention of the addressee together;

in concrete deixis, the base is a physical entity in the speech situation, while in abstract deixis the base is a reference-assigned chunk of space with stable coordinates in placing, the base is positioned for the attention of the addressee

- in placing, the base is positioned for the attention of the addressee articulator (such as the index finger or gaze).

- Note: Gaze plays an important role in deictic gestures; it projects its own attention-directing vector which may (a) reinforce a deictic hand gesture by providing a second vector oriented toward the same base and (b) assist in the management of attention direction during production of other gestures. Interacting:

- semiotic function: iconic (in that the hands imitate an action) and indexical (in that the shape of the hands is not the shape of the base, but is determined by the shape of the base); the hands are meant to look as if they were interacting with the base;

in holding, the hands are shaped to look as if they are holding the base

- in mimetic enactment, the hands are moving as if they are doing something to or with the base Modeling:

- semiotic function: iconic; the hands are meant to look as if they are the base

- in static modeling, the hand's shape imitates the shape of the base

- in analogic enactoment, the hand's movement imitates the movement of the base

Tracing:

- sermiotic function: iconic (in that the gesture imitztes drawing) and indexical (in that only part of the base is depicted, but the whole is referred to); the hands (more specifically, the fingers) are meant to look as if they were tracing the shape of some salient feature of the base, such as its ouline.

\section{Figure 4}

Semiotic devices used in some illustrative co-speech gestures.

with it, differing formally only in the presence or absence of hand movement. Analogic enactment may be grouped with static modeling, since both involve direct iconic representation of the base, differing formally only in terms of presence or absence of hand movement. Thus, there are four higher-level categories: deictic (indexical), interacting (indexing a base by iconically representing interaction with it), modeling (iconically representing a base directly), and tracing.

Figure 4 should not be interpreted to mean that any given gesture can be categorized as a unique instance of one of the terminal nodes. The figure does not categorize gesture types buth, rather, ways in which manual signs/gestures can signify. These can 
be combined in single gestures. This article does not deal with the full range of semiotic devices outlined in Figure 4, but in the interest of putting the gestural diagramming phenomenon into the context of a fuller semiotic system, it is desirable to begin by establishing the broader range of sign functions that illustrative manual signs and co-speech gestures may employ.

\section{Semiotics of Gesture Diagrams}

The phenomena described in this article involve only a subpart of the larger set of semiotic devices illustrated in Figure 4. The examples described below mainly involve abstract pointing and tracing. We consider now in more detail the device of abstract pointing and its relation to some of the other devices listed in Figure 4.

\section{Pointing and Abstract Pointing-Assigning Reference to Chunks of Space}

A concrete pointing gesture is an indexical signal involving some vector-projecting articulator (such as gaze or an index finger) oriented toward a physical object or location, in which the gesture is understood to have the communicative purpose of indicating that thing or some aspect of it (or, if the thing is merely a base, the intended deferred referent). ${ }^{7}$ It is easy to think that a concrete pointing gesture simply links a movement of the hand with a thing in the world, but this is wrong (Wittgenstein 1953:13-18). All forms of pointing set up a conceptual referent-the concept of what is being pointed to-and in concrete pointing, the conceptual referent happens to be mapped onto the same piece of space occupied by a physically existent base or referent entity. What is being indicated may of course not even be an entity, but perhaps a color exemplified by some entity (Wittgenstein 1953:16). Liddell (1995) points out the need to differentiate between the actual, existing physical space and what he calls real space - "an individual's conception of what is physically real in their current, directly perceivable physical environment" (Liddell 1995:23, emphasis added). If you indicate an object by pointing at it, you set up a conceptual referent (in your conceived "real space"), and this conceptual referent is instantiated by the physical thing. The physical thing thus becomes semiotically activated.

In abstract pointing (McNeill et al. 1993), we similarly set up a conceptual referent, but we do so by pointing not to a physical object or location, but to what I will refer to as a chunk of space. A chunk of space is a segment of physical space in the environment of a speaker that (1) is persistently delimited only by interlocutors' actively imagining it to be delimited; (2) is delimited by virtue of having been assigned, by gesture and speech in combination, a signifying relation to some referent active in the discourse; and (3) has stable spatial coordinates after having been established, in general not shifting in absolute space despite subsequent movements of the speaker's body. I conceive of such chunks as being no bigger than a soccer ball. A chunk of space inherits its characterization from publicly visible performance in interaction (along lines described by Goodwin 2000; inter alia). It is an invisible but stable target, created by people behaving as if a real thing were there, floating in shared space, when in physical reality there is nothing.

Liddell (1995) differentiates between two types of invisible chunks of spece used by American Sign Language signers. Surrogate spaces are "full-sized invisible entities", which have "body features, being viewed as present with the signer" (Liddell 1995:27-28). 
In signed languages, this often involves imagining a person physically standing by. Signs that are normally directed at different parts of the body of an interlocutor (e.g., forehead, chin, chest) can be similarly directed to different levels of height in physically empty space when referring to someone who is not present (cf. Taub 2001:79 ff). A model of a sandcastle sketched using co-speech gesture would be another example of a surrogate space. Token spaces, by contrast, are "featureless" reference-activated blobs of space "sized to fit inside the physical signing space where signs are articulated" (Liddell 1995:33). (In fact, they do not stay within the body-immediate gesture space, as will emerge below.) It is common, for example, for pointing gestures directed toward a speaker's left and right gesture space, respectively, to correspond with references to two distinct or contrasting ideas in a discourse (McNeill 1992:173 ff). This is an especially common strategy for pronominal reference in sign language (Liddell 2000).

For some purposes it is crucial to differentiate between surrogate and token space, but for other purposes it is useful to treat them together simply as cases of semiotically activated temporarily stable delimitations of thin air, and it is for this reason that I use the more general term chunk of space. Space itself is inherently undifferentiated, and the idea that chunks of it can be isolated in the first place is due to our imposed chunking of it, no doubt due to the effect that the human torso has on differentiating space (i.e., turning undifferentiated space into gesture space). Although space in general is undifferentiated, gesture space has inherent coordinates (i.e., in the human body that projects the space). Further, interactional space itself-for example, the general area in and around which interlocutors are situated-may be accorded internal structure according to a range of factors, associated with cultural conventions, interactional dynamics, and physical features of the space (Enfield 2003; Goffman 1963; Kendon 1977; Scheflen 1976; inter alia). Space, in the important sense of interactional space, thus cannot unproblematically be said to be undifferentiated. By pointing to empty space, we invite the addressee to imagine that something is there, in a manner analogous to the devices of tracing or virtual interacting shown in Figure 4. By looking like you are holding a ball, you can create in your interlocutor's mind the idea of a ball; analogously, by looking like you are pointing at a physical object, you create in your interlocutor's mind the idea of that object (cf. Haviland 2000:20).

\section{Gesture Diagrams: Structured Arrays of Reference-Activated Chunks of Space}

Reference-activated chunks of space can be multiplied and can together form structured complex wholes, such as the diagrammatic illustrations discussed in the next part of this article. The simplest case involves two chunks of space (to the left and right of the gesture space, respectively) referring to two distinct referents being tracked in a discourse, where the two chunks maintain a constant spatial relation to each other. Despite their ethereal nature, chunks of space are treated like objects, and the same can be true of whole structured arrays of multiple chunks of space. The reference-activated chunks and their configuration relative to each other show temporal persistence and a certain kind of spatial integrity or cohesion. The configurations can persist over time, as if a complex object were there in the real physical space.

In signs and gestures based on the technique of virtual interacting, such diagrams or models can be shifted, rotated, and resized. Suppose I use my hands to set up an image of a yardstick lying flat across my gesture space. I can then rotate it to face in any direction or pick it up and reorient it to be placed vertically, holding one end 
of it in one hand. In these virtual interacting moves (see Figure 4 above), I do not literally shift or rotate something but, rather, make movements that look as though I am shifting or rotating something. These movements index the intended base and referent. Now, suppose with my left hand, I hold one end of the virtual yardstick, and then with my free right hand I make a pointing gesture with my index finger to the tip of the yardstick (or, to be literal, to the point in space where the tip of the yardstick would be if it were real), at a point one yard directly above the point where my left hand is held. I can act as if the stick were really there, and, accordingly, I must assume the spatial cohesion set up by this model. If I point to the tip, I point to where the tip really would be, not to some point, say, out to my right. In this example, the hands do not portray the thing, but portray the image of holding and pointing at the thing, combining indexical and iconic devices.

\section{The Need for Adjustment or Revision of Gesture Diagrams}

Suppose that by a combination of gestures involving abstract pointing and virtual interacting, a speaker creates a model that efficiently communicates to her interlocutor the structure and layout of a sandcastle she built on the beach. This virtual model could persist in the interaction with little support from representational gestures. The two speakers in ensuing conversation could index-finger-point alternately to various parts of the structure (the moat, the main tower, the turrets), maintaining spatial cohesion of an imagined structure that they are imposing on the physical space in front of them. However, since these images are created online, without necessarily being well planned in advance, it happens that the cohesion of such complex structures can be problematic. Although one may have set up a structure that tums out to have faults, one may not want to be forced to obliterate it and start again from scratch.

There are at least three reasons why speakers who create gesture diagrams or modelssuch as a representation of a sandcastle-may find themselves in need of making some revision. First, they may make errors in their representation (e.g., I may have forgotten some component or I may have the proportions wrong and find myself unable to fit some part of the structure in). Second, they may reach the physical limitations of gesture space, placing some part of their diagram at the extreme of arm's reach, only to find that the next part of their developing diagram needs to be placed even farther out (or, indeed, finding that some part of the diagram needs to be placed closer to their body than they have allowed space for). Third, the semiotic motivation for the structural configuration of the diagram may change as the diagram develops. In a purely iconic diagram, this may be due to a change in perspective (e.g., from diagrammatic to viewer perspective; Emmorey 2001), while in a diagram that uses space metaphorically in depicting some nonspatial structure, the nature of the metaphorical mapping (e.g., whether only relative height carries a meaning or whether laterality becomes significant) may change as the interaction unfolds. Each of these motivations for adjustment or revision of a gesture diagram is exemplified in the data discussed below.

The question to be explored is thus not only how gesture diagrams are constructed, but also how they may be edited. In both of the examples described below, the speaker finds at a certain point that his evolving diagram is in need of adjustment. and certain techniques for making the required adjustment are observed. 


\section{Metaphorical Use of Space in Diagrams}

Both examples described in this article illustrate the metaphorical use of space in diagramming complex conceptual relationships (cf. Emmorey 2001). The structures they are designed to depict - namely, kinship relations - have no inherent spatial component. ${ }^{8}$ This situation in itself is of special interest in research on the relationship between meaning and space in that it involves the use of physical space in the communicative representation of nonspatial concepts. However, I expect the observations regarding cohesion and editing of abstract spatializations to apply just as well to concrete spatializations (i.e., to gestural diagrams that iconically represent spatial complexes, such as the structure of a sandcastle or the layout of an apartment). The differences concern the relation between the conceptual referent and the spaces utilized: When the domain to be diagrammed is abstract, the chunks of space will be token rather than surrogate spaces (Liddell 1995).

We now turn to description of the examples.

\section{Two Examples: Spatializing Abstract Conceptual Structures Using Gesture}

The video recordings discussed in this article are brief excerpts from informal interviews conducted with urban adult speakers of Lao, a southwestern Tai language, in Vientiane, Laos, June 2001. The interviews focus on the general issue of the Lao kinship system and kinship terminology in the Lao language.

Kinship is a useful domain for investigation of the spatialization, or concrete visualization, of abstract thought. Structures of kinship relations can be very complex but in general they do not constitute specialist technical knowledge. No socially associating individual in a community lacks conceptual representation of complex kinship networks. Structures of kinship relationship are inherently nonspatial, yet they are apparently easily visualized and spatialized in diagrams. ${ }^{9}$ At certain points during these interviews, the speakers engage in complex diagramming of kinship networks using representational co-speech gestures. This practice is most pronounced when they are presenting hypothetical scenarios to illustrate possible kinship relations (e.g., the distinction between first cousin and second cousin). These speakers spatialize complex sets of relations by diagramming them using co-speech gesture (mostly involving abstract pointing and tracing). In addition, much of the metaphorical structure of the diagrams - such as the use of distance and height as analogous to certain kinship relatedness - is also reflected in the accompanying linguistic expressions.

Our first example concerns restrictions on marriage between cousins.

\section{Example 1-Marriage between Cousins}

Lao speakers report that marriage between second cousins is regarded as generally permissible, whereas marriage between first cousins is regarded as permissible only under certain conditions (specifically, when the parent of the groom is the older sibling - not the younger sibling - of the parent of the bride) (Figure 5). ${ }^{10}$

The speaker in this example (Mr. Phouthong) is seated at the center in Figure 6 and subsequent figures in this section. The general topic of discussion is the Lao kinship term laan3, which can refer to (1) any child of one's own child, (2) any child of any of one's own siblings, or (3) any child of one parents' younger siblings. Thus, the denotation of laan3 covers that of English 'grandchild', 'niece', 'nephew'. 


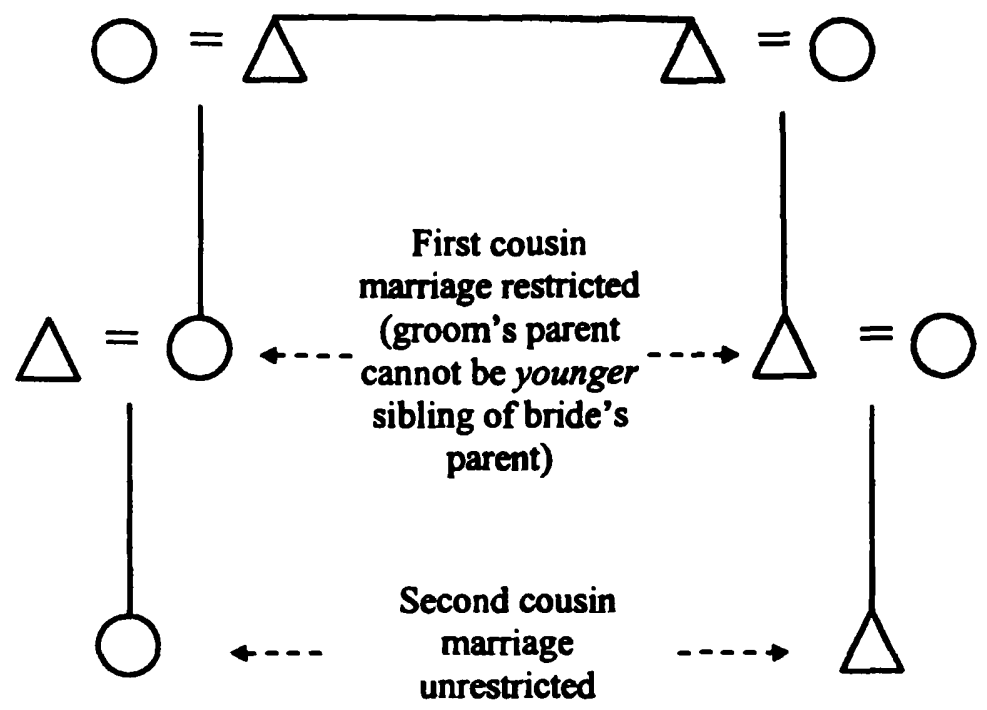

Figure 5

Lao speakers' reported attitudes to marriage among cousins.

and a subset of the denotation of 'cousin'. One issue concerning the topic of cousins is whether they can marry each other. The speaker in this example wants to explain that it is generally permissible for second cousins to manry, but not for first cousins (as illustrated in Figure 5). He decides to construct a hypothetical scenario in which he and the man seated to his right (Mr. Naak) are brothers, and they both have children (who are first cousins to each other), and these children have children in turn (who are second cousins to each other). Mr. Phouthong is now concerned with depicting relations between himself and his hypothetical brother, their hypothetical children, and their hypothetical children's hypothetical children.

Having invited his addressees to suppose that he is the younger brother of Mr. Naak, he begins as follows:"
(1) [khodj5] qaw3 [mia2] mii2 [luuk4] qdobs maa2 I take wife there.is child exit come '[I] $]_{\text {Fig }}$ take a [wife $]_{\text {Fig }}$, and we have a [child $]_{\text {Figg' }}$ '.

With his dominant (right) hand, the speaker makes three deictic gesture strokes, each coinciding with the verbal articulation of its intended referent ('I', 'wife', and 'child', respectively). These three gestures are made with relaxed, slightly curled B-hand (a hand shape in which the palm is open and flat, with fingers not curled and not spaced apart; McNeill 1992:87-88), each gesture slightly contralateral, to the speaker's front left, the first slightly to the side with bent arm (as shown in Figure 6), the second straightened to be more central but tilted slightly downwand (Figure 7), and the thind raised and fully extended to the front (Figure 8). ${ }^{12}$ 

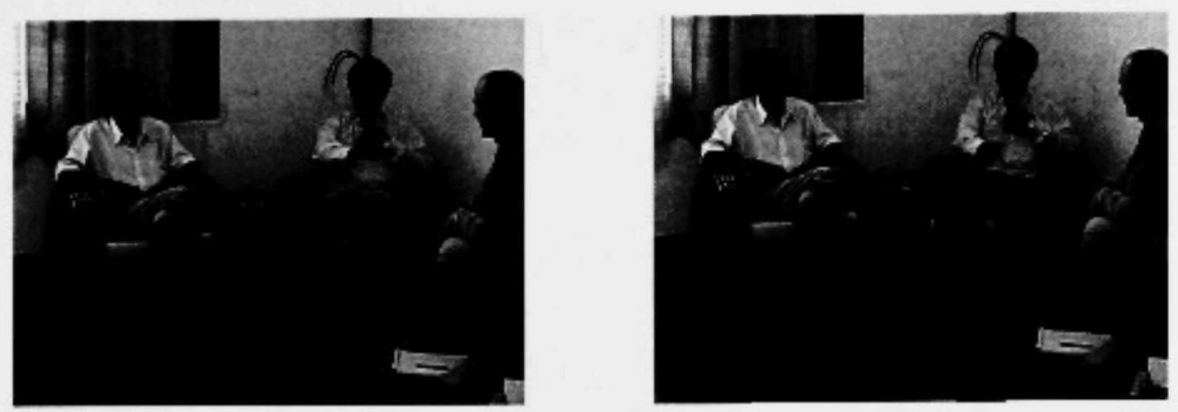

Figures 6 and 7

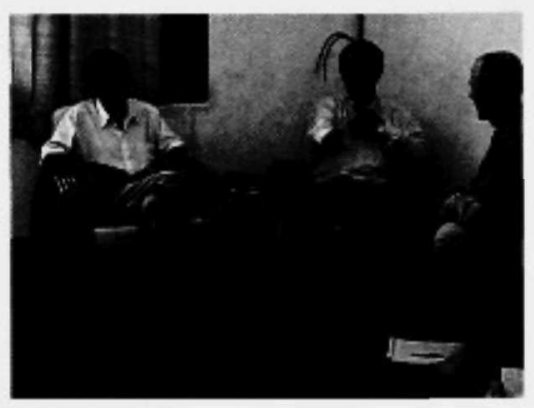

Figure 8

With this series of abstract pointing gestures, the speaker has drawn a line of descent, emanating straight out from his own body, pointing forward and slightly to his left.

Next, he turns his attention and gaze to Mr. Naak and almost exactly repeats the previous move, but now with reference to Mr. Naak, his older brother:

(2) la0 qaj0-[naak4] qaw3 [mia2] mii2 [luuk4] qoòk5 maa2 pcl older.brother-N. take wife there.is child exit come

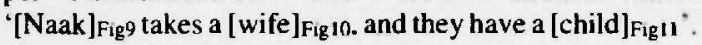

The three gesture strokes marked in Example (2) are illustrated in Figures 9, 10, and 11 , respectively.

Two things can be noted. First, the speaker's hand shape in Figures 6-11 remains more or less the same-a relaxed, slightly curled B-hand. Second, the speaker accompanies his abstract pointing gestures with eye gaze, reinforcing the deictic function of the gestures. Gazing at a manually indicated chunk of space puts extra attentional focus on it as a conversational referent, doubling the "baptismal" indexicality (Haviland 2000:20). Here the speaker is not gazing at his gesture, but farther away, so that the relevant chunk of space is located at the point of intersection of the vectors of his gaze and pointing gesture. ${ }^{13}$

The speaker has now set up two parallel lines of descent, emanating forward and away from himself and his brother, respectively, on a more or less flat plane. The important nodes on the lines of descent at this moment are the two brothers and their 

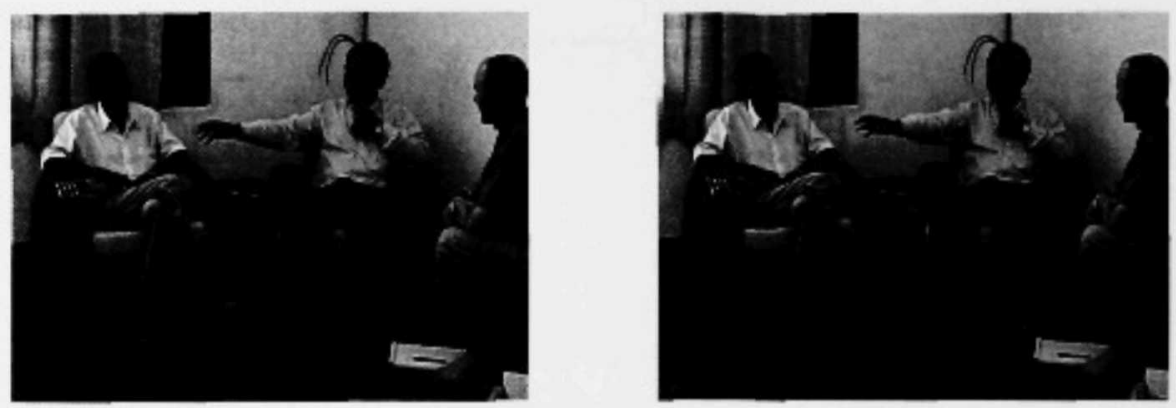

Figures 9 and 10

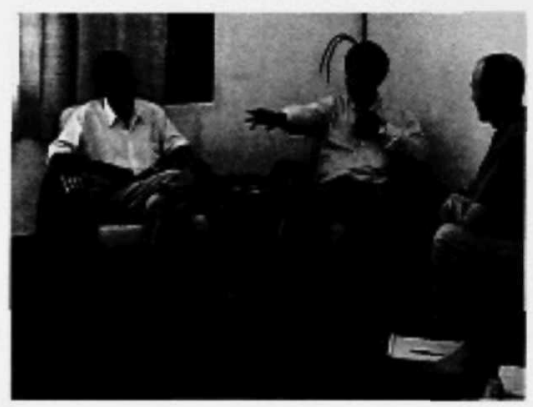

Figure 11

respective children. The children are denoted by the gestures shown in Figures 8 and 11, both of which involve the right arm fully outstretched. The current state of $\mathrm{Mr}$. Phouthong's diagram can be depicted as in Figure 12 (in which the two smaller white circles represent the speaker and his hypothetical brother, the two larger circles depict their respective children. and the connecting white lines represent the father-son relationship).

The speaker now explains that the two children can marry only if his own child (i.e., the child of the younger of the two siblings) is the bride. As he mentions the respective children, he points (with index finger and gaze) to the chunks of space that have just been set up to refer to these referents (i.e., the larger white circles in Figure 12). These two finger-and-gaze pointing gestures are illustrated in Figures 13 and 14.

(3) khan2 [luuk4 qaj0-naak4] han0 pên3 phu0-saaj2

if child older.brother-N. pcl be male

khan2 [luuk4 khơoj] pên 3 phu0-ñing2 ni0 mèènl qaw3 daj4

if child $I$ be female pcl is marry can

'If [Naak's child $]_{F_{i} 13}$ is a male and if [my child $]_{F_{i} i}$ is a female. then they can marry".

The hand shape is now clearly an index-finger pointing gesture (relaxed G-hand la hand shape in which the index finger is sticking out straight and all other fingers are curled over; McNeill 1992:87-88]), and, once again, gaze is aligned with these pointing gestures. such that looking and pointing are directed at the same space. 


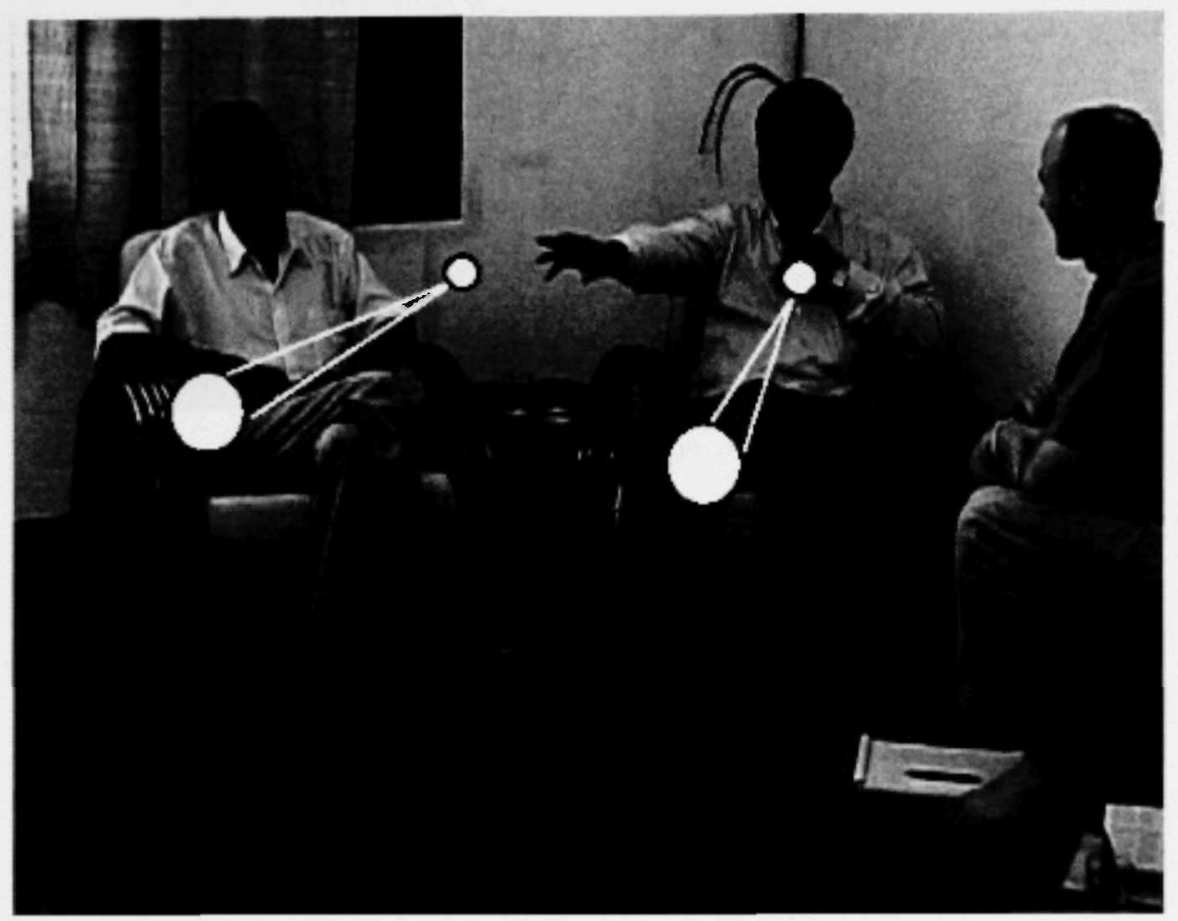

Figure 12

So far this is a typical use of abstract pointing to activate chunks of space with referential association to specific referents. Here, the speaker has set up no less than four such chunks (see Figure 12), and his deictic gestures in Figures 13 and 14 (accompanied by the speech in 3 ) demonstrate that the overall structure has cohesion and temporal persistence. That is, having set up a node referring to his own child in Figure 8, and having subsequently made farther gestures to more distant locations, he is able to point back to the same chunk of space in Figure 14 (more than seven seconds later).

Now, in order to continue his hypothetical outline, the speaker wants to bring the next generation of the family tree into the discussion, namely the children of the two cousins he has just established. He begins with hands relaxed in his lap, as illustrated in Figure 15.

He begins the next phase of his explanation with a metanarrative comment. explicitly announcing that he will now move on with his calculations.

(4) leèw4 la 0 [napl-thùü3] tò-tòòl paj3 baat5-ni0

finish pcl calculate connect-rdp go pcl

'So, now to [calculate $]_{\text {Fig } 16}$ the further connections'.

The gesture accompanying this comment is a simultaneous raising of the hands followed by straightening of the elbows until the arms are forward and outstretched. $\mathrm{He}$ is representing the two children of the first generation (first introduced in Figures 8 and 11 and marked as large white circles in Figure 12), one on either side. 

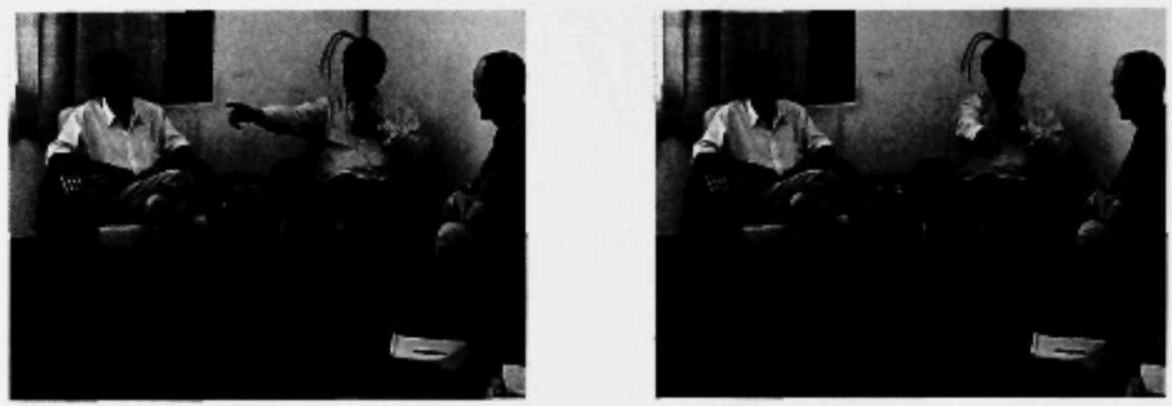

Figures 13 and 14
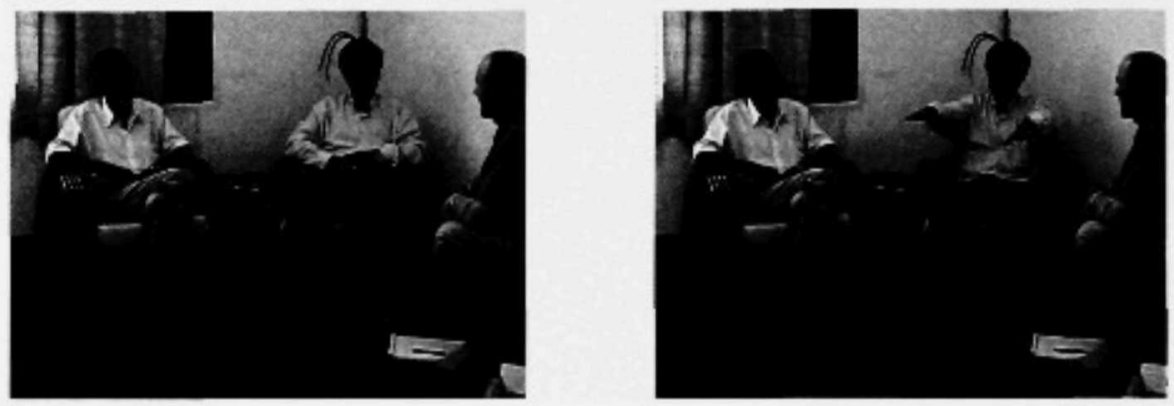

Figures 15 and 16

Now the speaker encounters a representational problem. He has so far created a diagram depicting the first generation below himself and his brother. This is shown in Figure 12 and more abstractly in Figure 17a below. His problem now is to add to this diagram the next generation-that is, the children of his children as well as the children of his brother's children. He needs to extend the present diagram so as to produce Figure $17 \mathrm{~b}$.

Given the speaker's current physical orientation and the logic of his developing diagram. he is unable to proceed without making some adjustments. His fully outstretched arms (shown in Figure 16) indicate the first set of children. The diagram is motivated by a metaphor that maps generations of descent onto steps forward and away, and since his arms are already fully outstretched, he is lacking the necessary forward reach to represent the next generation. This situation is depicted in Figure 18, a schematic representation of Mr. Phouthong's physical relationship to the diagram he is working on, as it is at the stage depicted in Figure 16 and Figure 17a.

We now see how the speaker solves the problem with a combination of two devices. Beginning from the position shown in Figure 18, the speaker experiences disfluency. as he slightly bends his elbows and brings his dominant (right) hand forward and across with his left hand held in space, relaxing only slightly:

(5) [lang 3 -caak 5] after

[After|fig19 . . (1 8 si $^{\circ}$ 

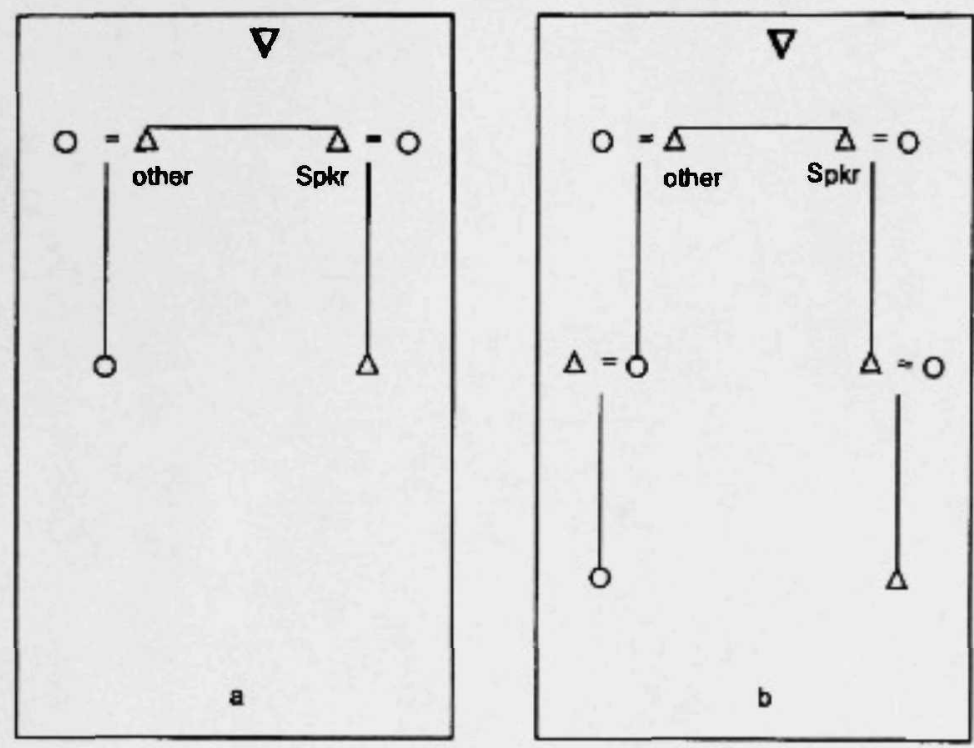

Figure 17a

First generation of descent from speaker and speaker's brother.

Figure 17b

First and second generations of descent from speaker and speaker's brother.

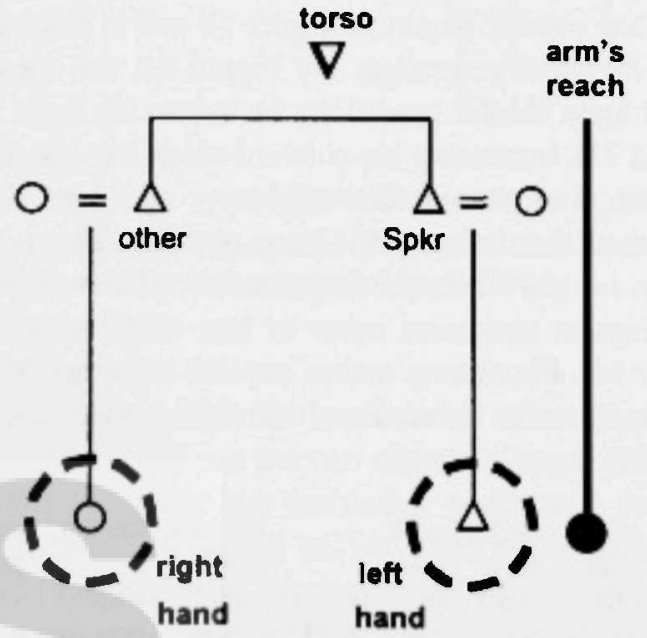

Figure 18

Mapping of speaker's gesture (Figure 16) onto diagram of first generation of descent (Figure 17a). 


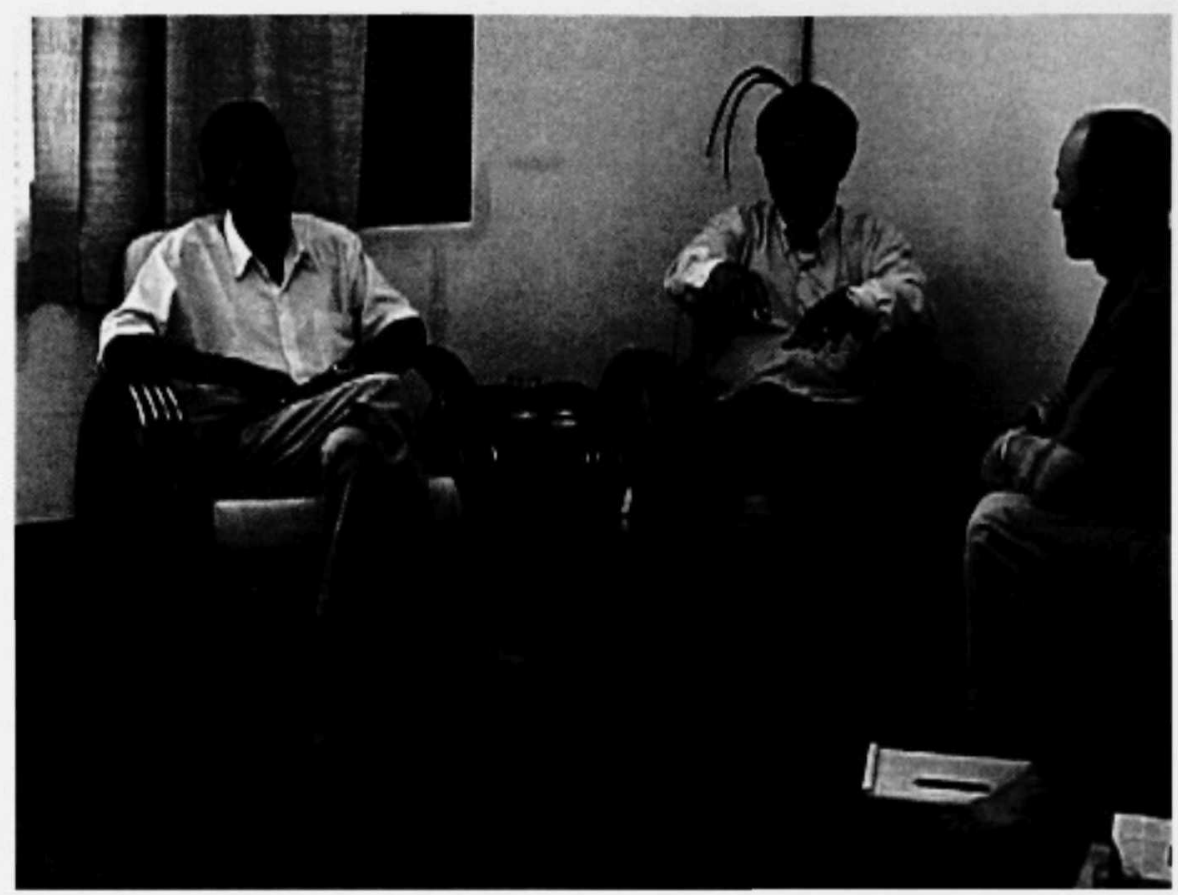

Figure 19

Next, Mr. Phouthong performs a hold-and-drag move with his left hand, bringing the first-generation chunk of space, anchored to his left hand, closer in to his body. This action has already begun in Figure 19 and is finished by the time the speaker mentions the third generation. By Figure 2l. the speaker's left hand is now resting on his knee. At the same time, he moves his torso forward (compare Figures 19, 20, and 21), increasing his outward reach into space. When he moves forward, the diagram does not automatically move with him, despite the fact that it was first established in relation to his torso position. This is visible in that the speaker appears to be physically leaning forward and over the diagram. Once established, the diagram maintains more or less stable coordinates in absolute space. By the time Mr. Phouthong makes explicit reference to his grandchild in the diagram, his body is far forward and his right arm is once again fully outstretched (Figure 21). ${ }^{14}$

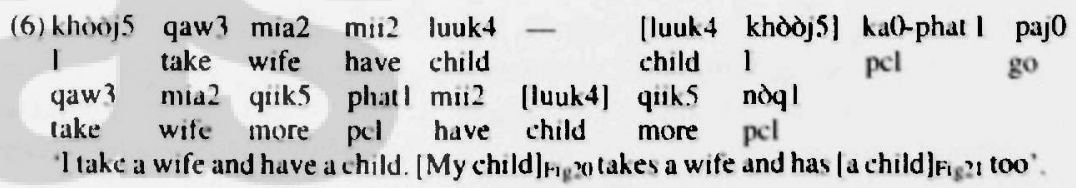

This second move can be illustrated more schematically as follows (as a second step from Figure 18. showing the transition from Figure 17a to Figure 17b). WwW.anthrosource.net 

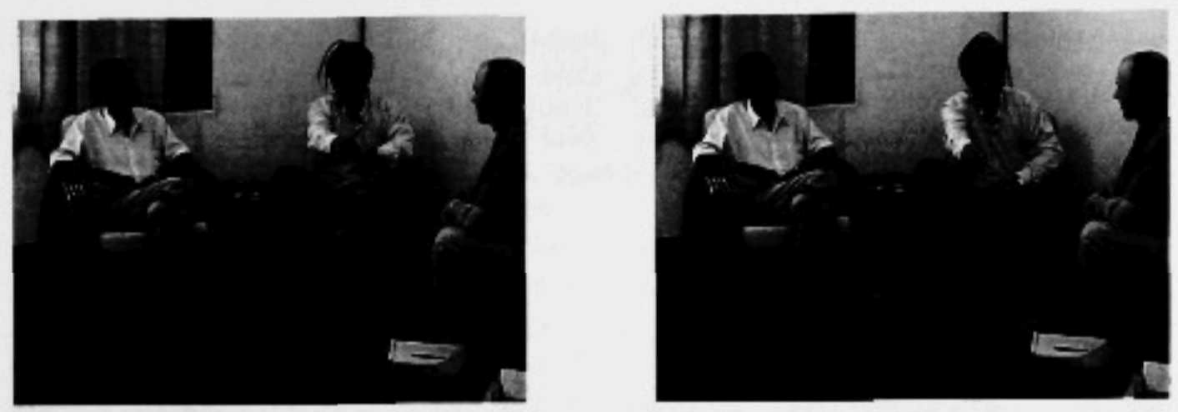

Figures 20 and 21

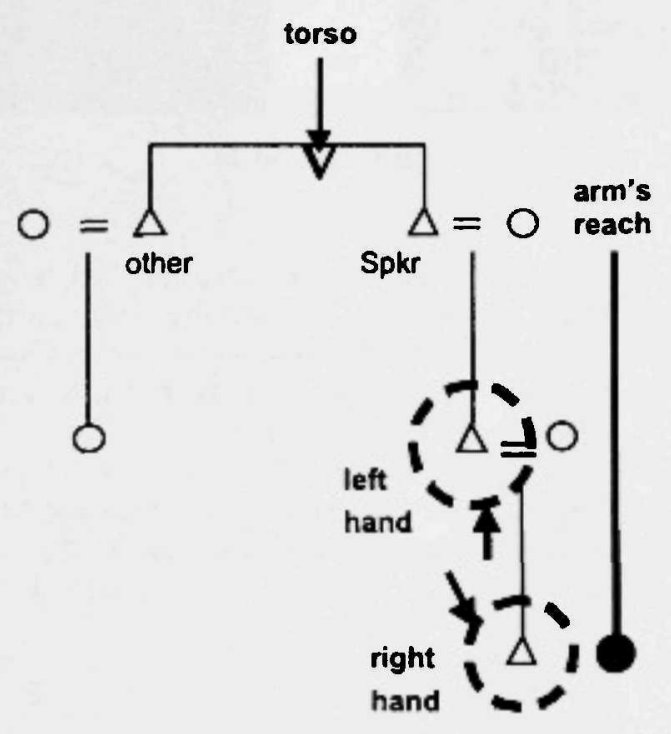

Figure 22

Mapping of speaker's sequence of gestures (Figures 19 and 20) onto partial diagram of first and second generations of descent (cf. Figure 17b).

The adjustments that the speaker has made to his own side of the diagram have resulted in there being now not one but two chunks of space positioned in a line on the sagittal axis, standing for the two descending generations, respectively. He now explicitly creates the same adjustment on Mr. Naak's side of the diagram, but assuming a symmetry to the diagram, he apparently no longer needs to hold the firstgeneration chunk of space and drag it closer in to Mr. Naak's body. He merely uses abstract pointing gestures to create the relevant two distinct chunks of space referring to the further generations. Mr. Phouthong almost exactly repeats the structure of what he said in Example 6, only now referring to Mr. Naak: 
$\begin{array}{llllllll}\text { (7) qaj0-naak4 } & \text { qaw3 } & \text { mia2 } & \text { mii2 } & \text { [luuk4] } & \text { - luuk4 qaj0-naak4 han0 } \\ \text { older.brother-N. } & \text { take } & \text { wife } & \text { have } & \text { child } & \text { child } & \text { older.brother-N. pcl } \\ \text { phat l qaw3 } & \text { mia2 } & \text { phatl mii2 } & \text { [luuk4] qiik5 } & & \\ \text { pcl take } & \text { wife } & \text { pcl } & \text { have child } & \text { more } & \end{array}$

'Naak takes a wife and has [a child] Fig23. Naak's child takes a wife and has [a child]Fig24 too'.
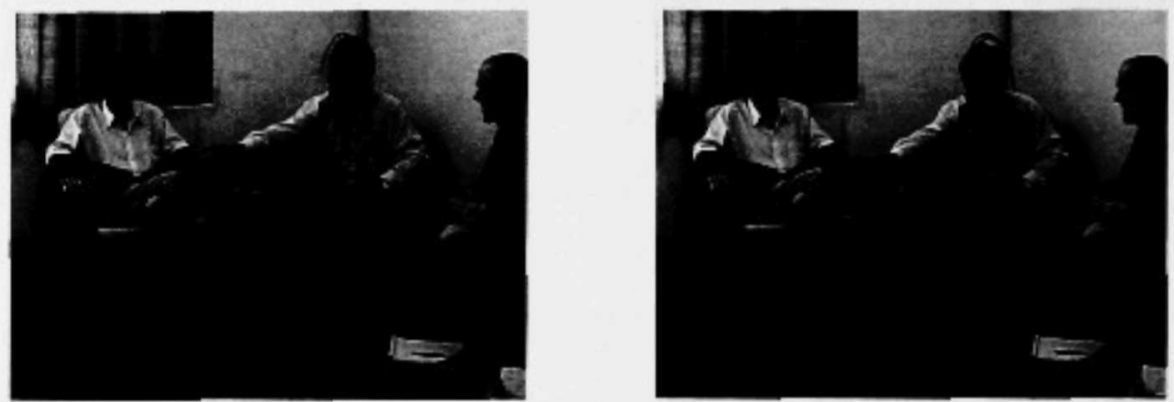

Figures 23 and 24

The speaker is now leaning visibly farther forward than he was in the earlier sequence shown in Figures 9,10, and 11, increasing his reach into gesture space. Although these chunks of space are abstract referents, or in Liddell's terminology token spaces, they are located not in the gesture space, but beyond it (pace Liddell 1995:33).

Mr. Phouthong has now created a virtual diagram of the following form. (In this diagram, $(\mathrm{N} \downarrow)$ and $(\mathrm{P} \downarrow)$ represent the viewpoints of $\mathrm{Mr}$. Naak and $\mathrm{Mr}$. Phouthong from where they are sitting, and boldface letters refer to nodes on the diagram: $(\mathbf{N}=\mathbf{M r}$. Naak, $\mathbf{P}=\mathbf{M r}$. Phouthong), and subscript numbers refer to generations of the men's children.)

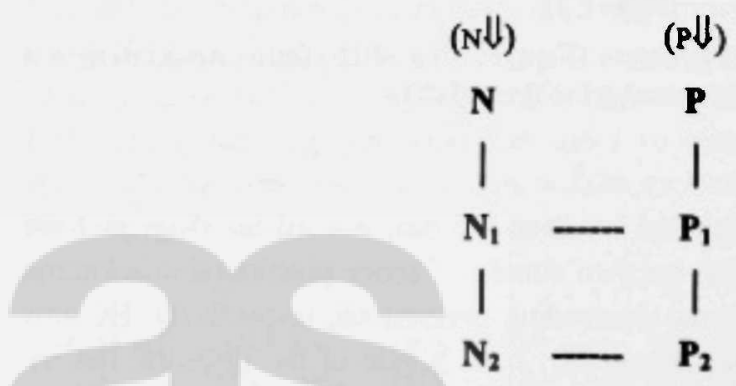

Figure 25

Graphic depiction of a gesture diagram representing first and second generations of descent from speaker and speaker's brother (cf. Figure 17b, Figure 26). 
The gesture diagram itself is different from Figure 25 in one important way, namely that whereas the artifactual signifying material in Figure 25 is ink on the page, there is no artifactual signifying material corresponding to the gesture diagram illustrated in Figures 6-24. The hand is a visible artifactual signifier, but it is not the diagram. The hand is not analogous in this case to the ink on the page, but to the pen that inscribes it. Further, when the hand does signify in a manner analogous to ink on paper (e.g., when serving a direct modeling function), it does so only evanescently. Unlike ink on paper, it does not endure, and the diagram thus has an inescapable temporality. Although the diagram is wholly in the mind of the interlocutors involved, as a structured set of semiotic associations between chunks of space and conceived referents, it nevertheless has structural integrity and temporal persistence. Figure 26 offers an illustration of the diagram as it would be projected by the interlocutors in the actual space:

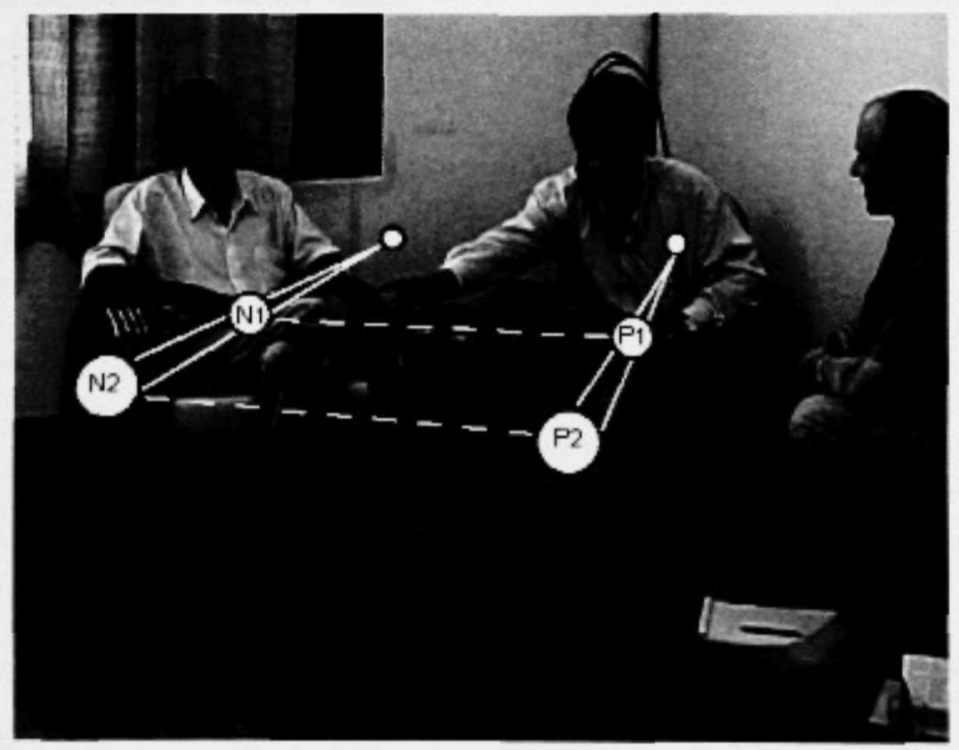

Figure 26

Now that Mr. Phouthong has established this structure, he can continue his exposition while free to indicate the various nodes with spatially oriented deictic gestures as he makes reference to different individuals concerned.

He now states that marriage between second cousins (i.e., between $\mathbf{N}_{2}$ and $\mathbf{P}_{2}$ in Figure 25) is permissible. Throughout the utterance he has his arms outstretched, index fingers deictically referring to the two grandchildren, while his hands are panning repeatedly, outward to the sides (as shown in Figure 27) and inward to the center (as shown in Figure 28) in a representation of their coming together in marriage. The hands move as if tracing back and forth along the dotted line nunning between the two largest white dots in Figure 26. The gesture overlaps fully with the utterince: 


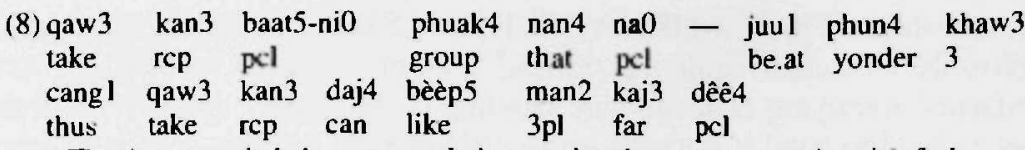

'(They) get married, those ones - being yonder. they can marry, since it's far'.
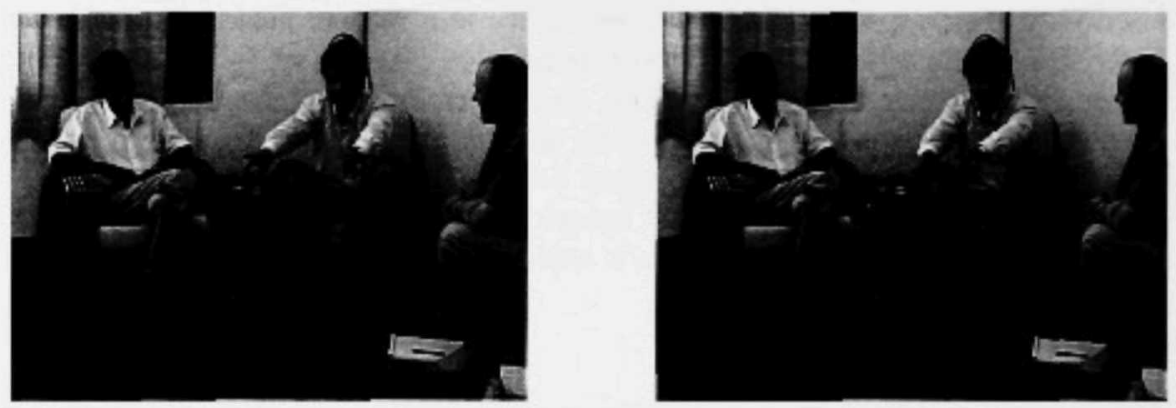

Figures 27 and 28

It is probably impossible to say whether this gesture employs tracing (in which a line between $\mathbf{N}_{2}$ and $\mathbf{P}_{2}$ is drawn-cf. Figure 26-representing the link between them) or an analogic enactment (of the event of their coming together). In either case, however, it is especially interesting to note that both the tracing and the enactment are played out at a distance, beyond the gesture space, projected by the pointing index fingers. This can be seen by the fact that the speaker's gaze appears to be not on his fingertips but at points in the distance.

Next, Mr. Phouthong remarks that the marriage of first cousins is not preferred. In doing so, he draws his hands in closer to his body, bending his elbows and angling the hands to point down (onto the flat plane of the gesture diagram), deictically referring now to $\mathbf{N}_{1}$ and $\mathbf{P}_{1}$ in Figure 26. The greater proximity of these two nodes is reinforced by his gaze behavior. Rather than gazing out beyond where his hands are (as he seems to do in Figures 27 and 28), he now looks down onto his hands, first at $\mathbf{N}_{\mathbf{1}}$ (Mr. Naak's child), then at $\mathbf{P}_{1}$ (his own child), as shown in Figures 29 and 30. respectively:
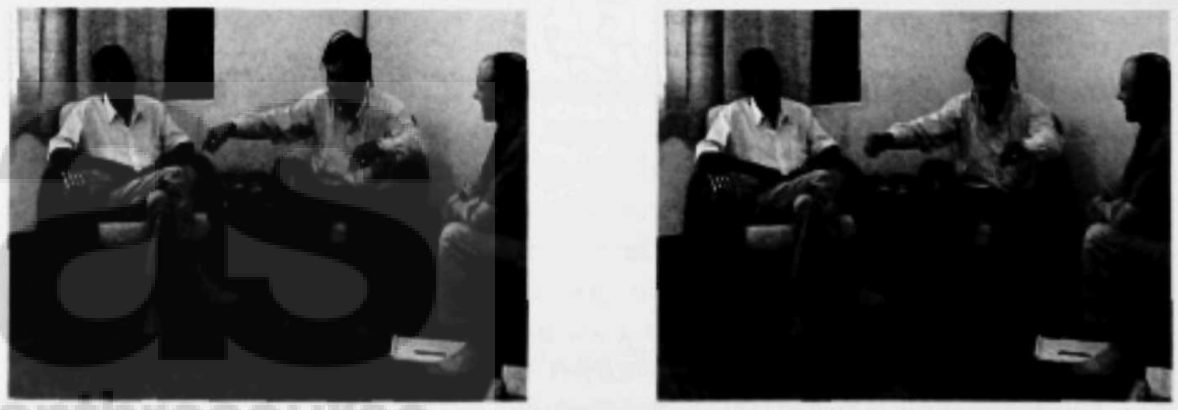
(9) [khan2] vaal juul [thit0-thit2] kan3 ni0 phatlif comp be.at close-rdp rcp pcl pcl khaw3 phatl bó0 haj5 qaw3 $3 \mathrm{pl}$ pcl neg allow marry '[If] Fig29 they' re close [together] Fig30. like so, they don't allow them to marry".

Note that in both Examples 8 and 9 the speaker uses a spatial metaphor in speech as well as gesture, using terms for spatial distance (i.e.. 'far' and 'close') to express kinship relations.

Next, Mr. Phouthong is able to exploit the presence of the diagram for further comment on the use of the kinship term laan 3 'grandchild, nephew, niece, cousin via parent's younger sibling'. He first refers back to the two grandchildren:

$\begin{array}{lllllll}\text { (10) khan2 val } & \text { val sommutl vaal } & \text { [pên3 } & \text { laan3] } & \text { ni0 } & \ldots \\ \text { if comp suppose comp } & \text { be } & \text { laan3 } & \text { pcl }\end{array}$

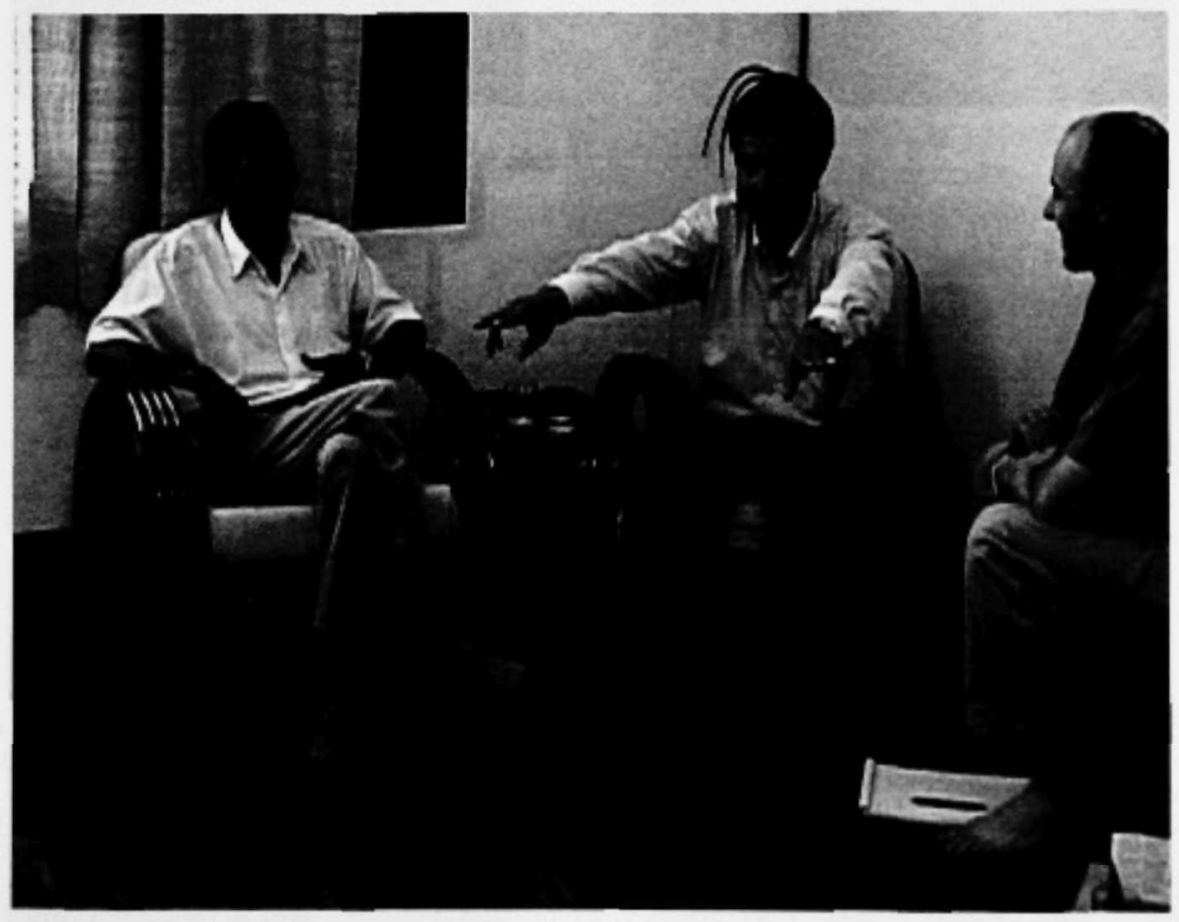

Figure 31

Earlier in the conversation. the term laan3 had already been defined as the child of one's own child', and in Figure 31 Mr. Phouthong is referring by his gesture to the two grandchildren who would be referred to as laan 3 in this sense by both men (i.e, $\mathbf{N}_{2}$ and $\mathbf{P}_{2}$ in Figure 26). His hands are fully outstretched, pointing well forwand.

Mr. Phouthong now goes on to add that the two men would also each use the term $\operatorname{laan} 3$ to refer to the child of the other (i.e., to the child of one's own brother): 
$\begin{array}{llllllll}\text { (11) [khòj5] hòòng4 } & \text { [luuk4] } & \text { qaj0-naak4 } & \text { ka0 nang2 pên3 laan3 juu2 } \\ \text { I } & \text { call } & \text { child } & \text { older.brother-N. } & \text { pcl still be } & \text { laan3 } & \text { pcl }\end{array}$ '[I] Fig32 still call Naak's [children $]_{\text {Fig33 }}$ laan3, nevertheless'.

In making this utterance, he first index-finger-points to his own chest (referring to 'I', Figure 32), and second to Naak's child, with index-finger-point and gaze directed at the node $\mathbf{N}_{1}$ of Figure 26 (as illustrated in Figure 33):
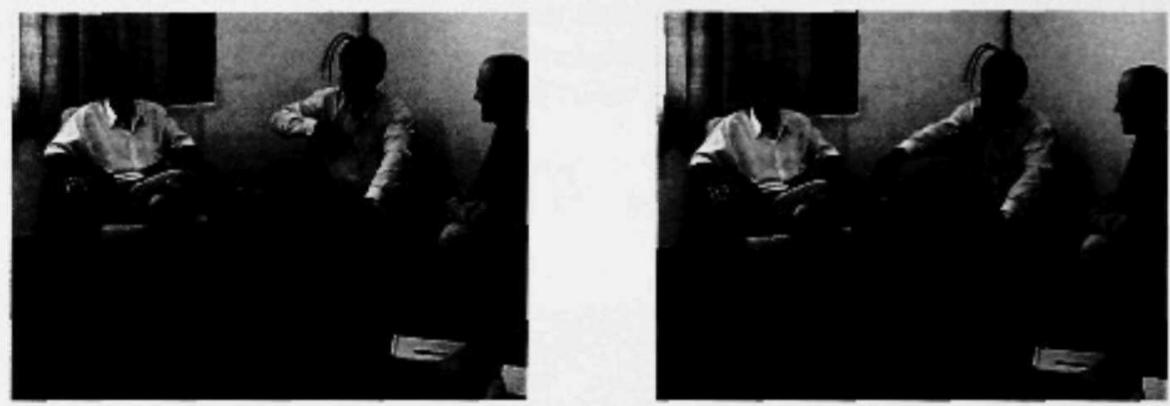

Figures 32 and 33

Following this, he states the converse, pointing first to $\mathrm{N}$ (Figure 34) and second to $\mathbf{P}_{1}$ (Figure 35) on his diagram (cf. Figure 26):

(12) [qaj0-naak4] hòòng4 [luuk4 khöòj5] ka0 pên3 laan3 khùù2 kan3 older.brother-N. call child I pel be laan3 like rep '(and) $[\mathrm{Naak}]_{\mathrm{Fig}} 34$ calls [my children]Fig35 laan 3 , $100^{\circ}$.
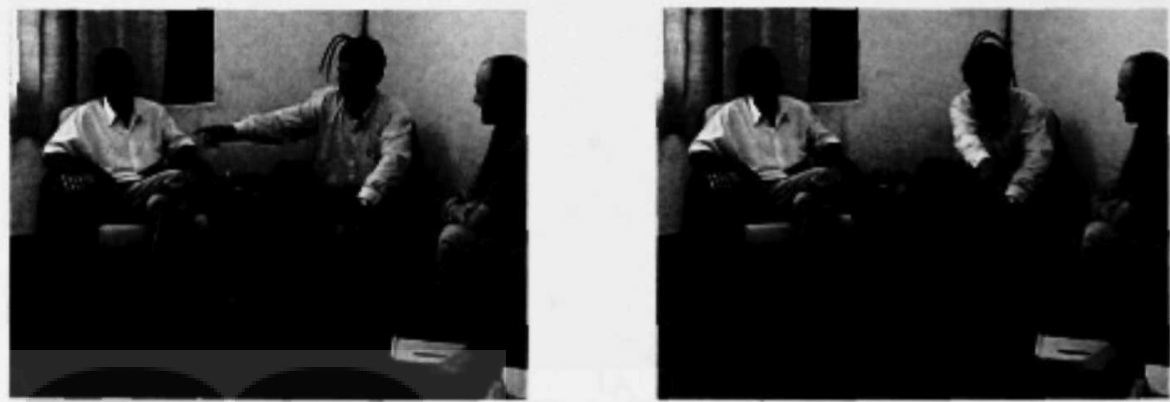

Figures 34 and 35

The deictic gesture shown in Figure 35 indicates the node $\mathbf{P}_{1}$. Greater laterality and downwardness in angle of the outstretched-arm index-finger pointing gesture indicitles that the node is closer to the speaker's body. In addition. the speaker's fixation of gase on the proint, looking at the relevant chunk of space as if he were looking at a thing. puts greater foxus on it as an indexically created referent. 


\section{Discussion of Example 1}

In this example, the speaker utilizes not only his own gesture space, but also the gesture space of his interlocutor, borrowing it for the purpose of his exposition. Mr. Phouthong's diagram (represented abstractly in Figure 25; cf. Figure 26) bears an uncanny resemblance to the scientific diagram shown in Figure 5. Are we to assume that this particular spatial representation is motivated rather than merely arbitrary? There may be in this case a motivated association between the spatial layout of the diagram and the structure it is meant to represent. (McNeill terms it "metaphoric" rather than "iconic" since the homology is not "copied from the world" but rather "created by the mind" [1992:145].) But unlike the illustrations in Figures 5 and 25, Mr. Phouthong's diagram relies on the mental projection of his interlocutor for it to work, indeed for it to exist. Ink-on-paper illustrations similarly require a mental component in order for them to signify, but in the case of the gesture diagram no physically discrete signifier need persist. Mr. Phouthong makes heavy use of abstract pointing gestures, coordinated closely with speech and gaze, to activate distinct chunks of space, assigning each one reference to a distinct but related idea, and the virtual structure he creates remains in place for some time. The diagram has spatial cohesion and temporal persistence, especially clear in that points on it become referents for later deictic gestures. In sum, Mr. Phouthong successfully spatializes and makes visually accessible an inherently nonspatial and invisible structure.

Given that the production of gesture diagrams has a necessarily temporal dimension, there is always the possibility of running into problems in the construction of the diagram. This example has illustrated one such case, and we have observed one speaker's techniques for overcoming the problem of having painted himself into a corner. The moment when Mr. Phouthong has difficulties in Example 1 is illustrated in Figures 16-21 (and accompanying Examples 5 and 6). He has basically run out of gesture space and has not foreseen the constraints that his diagram presents. His initial move of setting up chunk-of-space reference points for the first generation (the two first cousins) with full arm extension to the front results in a problem when it comes time to add the next generation out. He has no more forward extension physically available (cf. Figure 18). He needs to spatially differentiate his already established first set of children from the next generation, and this means bringing in the former, closer to himself, and establishing the latter in a space farther out (cf. Figure 22). He achieves both by combining the following three editing techniques:

\section{(1) hold-and-drag}

hold (by virtual holding) a reference-activated chunk of space and drag it (by mimetic enactment) to a preferred location in the gesture space (in this case, closer to the body; Figures 16-22);

(2) hold-and-work-with-free-hand

hold (by virtual holding) a reference-activated chunk of space while the free hand works on an extension or redesign of some part of the diagram (Figures 16-22);

(3) move-body-into-new-space

move the body (in any direction), allowing the hands to reach into new space not hitherto accessible (compare Figures 19 and 20); meanwhile, the diagram maintains absolute spatial cocordinates and does not shift with the movement of the speaker's body.

This completes the description of Example 1. Our next example concerns kinship terminology used between siblings. 


\section{Example 2-Use of Kinship Terms between Siblings}

In this example, Mr. Naak is discussing the meaning of the two terms qaaj4 'older brother' and nòòng4 'younger brother'. He will eventually depict a structure along the lines of the following schematic diagram:

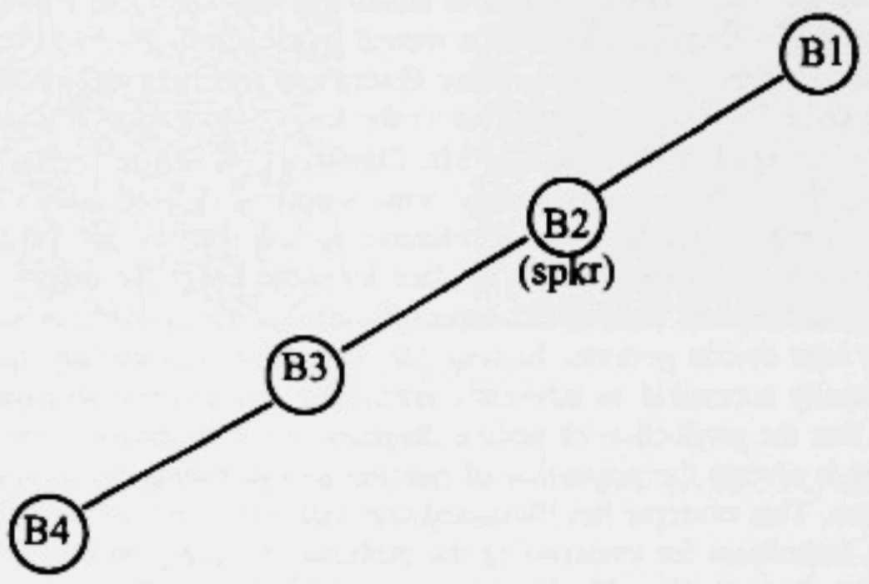

Figure 36

Schematic diagram of the relationship between four brothers, numbered 1 to 4 in order of birth.

I will henceforth use B1, B2, B3, and B4 to refer to these individuals. The speaker is $\mathrm{B} 2$.

The speaker states that he himself has one older brother, for whom he uses the term qaaj4 'older brother'. When asked to define the term qaaj4. he first states that the term refers to 'a male who is born before (you)'. This definition is too broad (e.g.. it would be a perfectly good definition for phòl ' father'), and so I ask him to be more specific. He then sets out to differentiate his father from his older brother. both of whom are males borm before him. He first sets up with his gesture and gaze a reference point for his father. index-finger-pointing to a space in the lower portion of gesture space immediately in front (Figure 37). Second, he points to himself by tuming his index-finger point slightly back in toward his body (Figure 38).

\begin{tabular}{|c|c|c|c|c|}
\hline $\begin{array}{l}\text { (13) maaj 3-khusm? } \\
\text { mean }\end{array}$ & $\begin{array}{l}\text { val meènl } \\
\text { comp be }\end{array}$ & $\begin{array}{l}\text { [phoidl] } \\
\text { father }\end{array}$ & $\begin{array}{l}\text { khow)ng.3 } \\
\text { of }\end{array}$ & $\begin{array}{l}\text { |haw2) } \\
\text { I }\end{array}$ \\
\hline
\end{tabular}



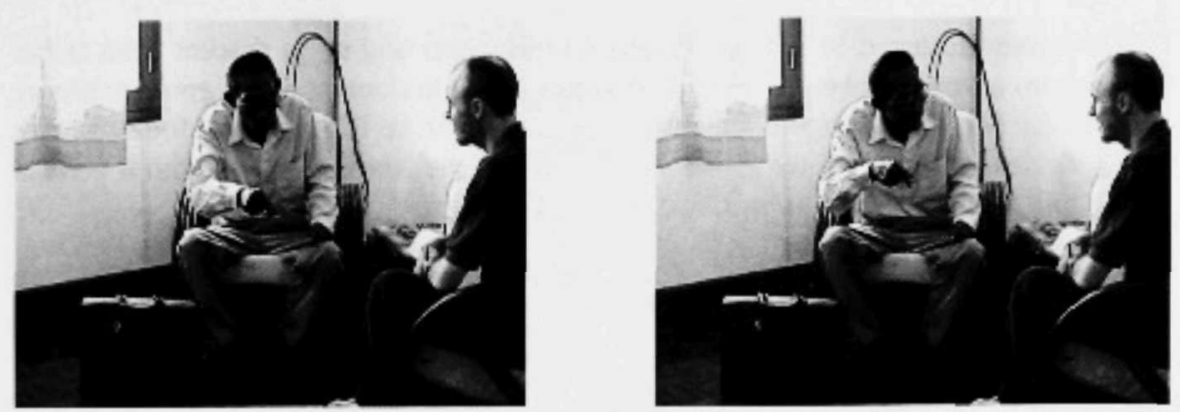

Figures 37 and 38

The gesture referring to 'father' (Figure 37) is reinforced by gaze toward the referent chunk of space, but the gesture referring to 'me' (Figure 38) is not.

Mr. Naak immediately continues, with 'father' as topic, introducing the first son of the father (i.e., the speaker's older brother B1):

\begin{tabular}{|c|c|c|c|c|c|c|c|c|}
\hline $\begin{array}{l}\text { 4) phuu5 } \\
\text { person } \\
\text { phuu } 5 \\
\text { person }\end{array}$ & $\begin{array}{l}\text { nii4 } \\
\text { this } \\
\text { haj5 } \\
\text { give }\end{array}$ & $\begin{array}{l}\text { nii4 - } \\
\text { pel } \\
\text { [kamneet5] } \\
\text { be.born }\end{array}$ & $\begin{array}{l}\text { pên3 } \\
\text { be } \\
\text { phuu5 } \\
\text { person }\end{array}$ & $\begin{array}{l}\text { phuus } \\
\text { person } \\
-\end{array}$ & $\begin{array}{l}\text { haj5 } \\
\text { give } \\
\text { phuu5 } \\
\text { person }\end{array}$ & $\begin{array}{l}\text { kamneet } \\
\text { be.born } \\
\text { [qaaj4] } \\
\text { qaaj4 }\end{array}$ & $\begin{array}{l}15 \\
\text { nio } \\
\text { tpc }\end{array}$ & $\begin{array}{l}\text { keet } 5 \\
\text { born }\end{array}$ \\
\hline
\end{tabular}

This one here-is the one who brings about the creation - is the one who brings about the [creation] $]_{\mathrm{Fig} .39}$ (of) the-this [qaaj4 $]_{\mathrm{F}_{1 \mathrm{~g}} 40}$ (the oldest brother)".

The gestures of Mr. Naak's right hand are complex and difficult to interpret, and here I note just two clear points in the sequence, marked with square brackets in Example 14. First, a metaphoric/deictic gesture corresponds to the father's bringing about the creation of the first son, with downward-pointing basket hand depicting creation, as shown in Figure 39. Second, a clear index finger-pointing gesture (Figure 40) activates a chunk of space low in the speaker's gesture space. directly in front, as a reference point for the first-born son (the speaker's older brother):
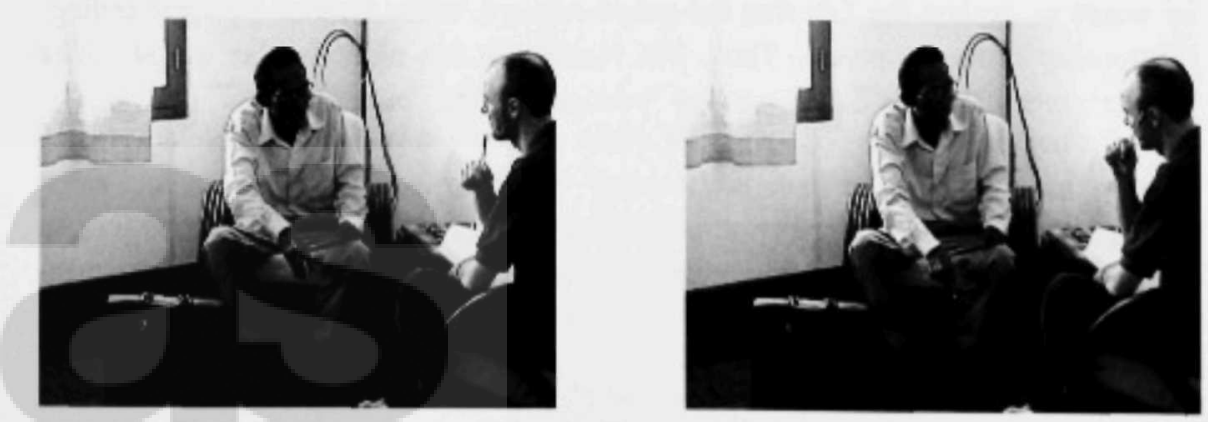

Figures 39 and 40 
The move illustrated in Figures 39 and $\mathbf{4 0}$ metaphorically maps descent from father to son onto a vertical plane. This is in contrast to the horizontal away-going mapping selected by Mr. Phouthong in Example 1 above. It can be illustrated as follows, with white circles representing the father $\mathrm{Fa}$ above, and the son $\mathrm{Bl}$ below, with a vertical white line between them indicating their relationship:

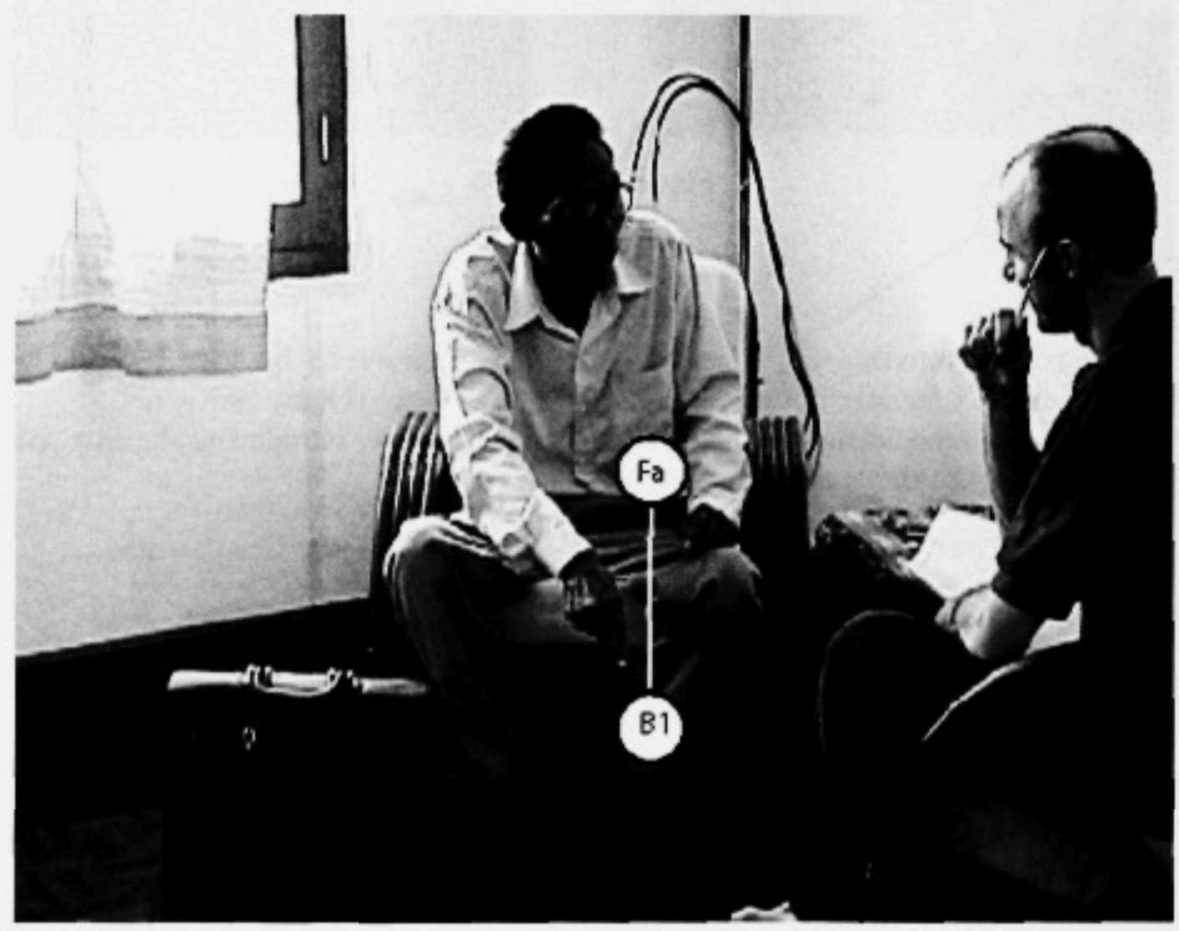

Figure 41

Throughout the rest of this example, however, Mr. Naak is never again concerned with the relation between father and son and does not mention the father again. From this point, he is concerned exclusively with the relation between siblings. In particular. he wants to explain the fact that the qaaj4-nòng4 'older brother-younger sibling relationship is nonreciprocal. Thus, Mr. Naak calls his older brother qaajt 'older brother', whereas he is called nòngt 'younger sibling' in return.

In the next part of the sequence, Mr. Naak reiterates a point he has already made, namely that the first-born male is the qaajt 'older brother' to all others. and as he finishes this statement, he uses a thumb-and-forefinger-touching gesture, pointing up (shown in Figure 42) as if presenting the older brother for his addressee's consideration:

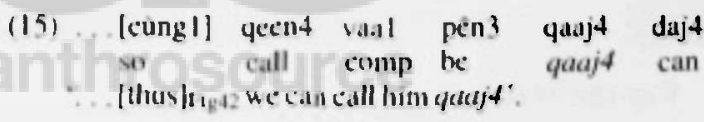




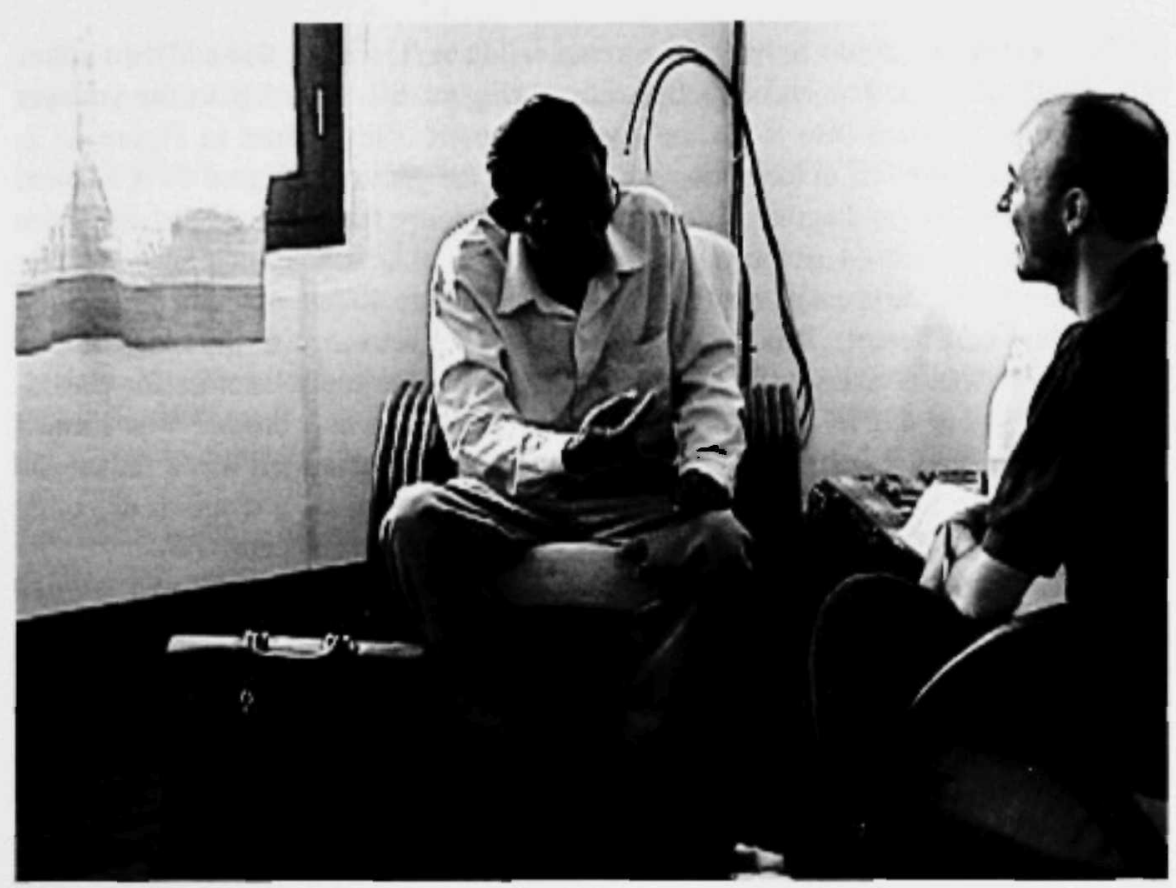

Figure 42

He now states his own position in the sibling ranking, which, as already established earlier in the interview, is second brother.

(16) [haw2] la0 pên3 [nòòng4] keet5 phuu5 thiil sỏöng3 I pcl be younger.sibling born person ord two

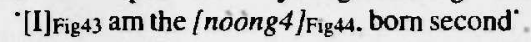
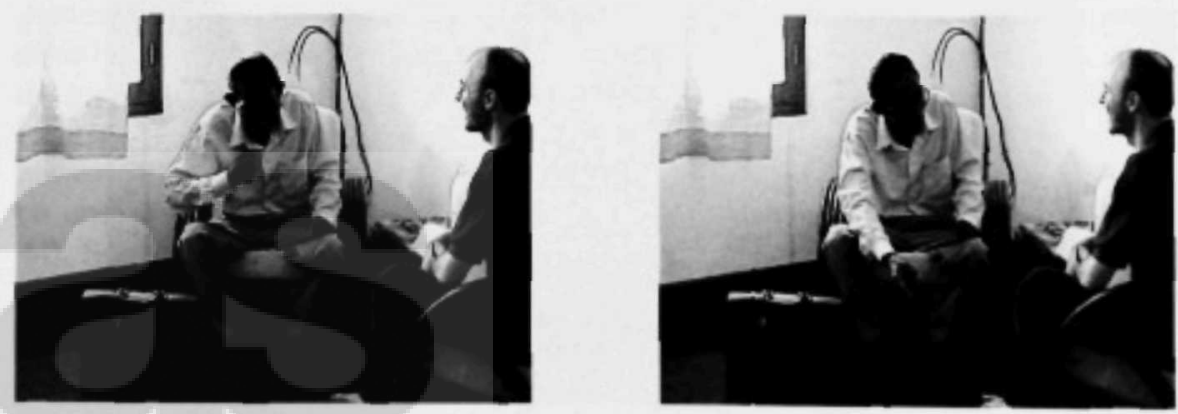

Figures 43 and 4 
The speaker first points to himself, corresponding to 'I' (Figure 43) and then points to a chunk of space low and directly in front (Figure 44), referring to the younger brother, who happens also to be the speaker himself. The gesture in Figure 43 is oriented toward himself in the interaction, whereas the gesture in Figure 44 is oriented toward himself in the diagram. The reader will no doubt have noticed that the space pointed to in Figure 44 (referring to the speaker as B2) is the same space as that which referred to the speaker's older brother B1 in Figure 40 (although the orientation of the hand is different). It is possible that the earlier reference to the older brother in Figure 40 was deactivated when the speaker raised the oldest brother for consideration in Figure 42. In any case, at the time when the first brother was located below and in front (i.e., in Figure 40), what was being diagrammed was a father-son relationship (cf. Figure 41). Now the speaker is embarking on a diagram depicting the relationships between brothers ranked by relative age (see Figure 36 ).

The next thing Mr. Naak does is to bring in a third brother, his own noòng4 'younger sibling'. This is achieved by contrast with the reference point he has just created in the low front gesture space, slightly to his left (referring to himself as second brother in Figure 44). Already pointing at the space he has created for reference to himself as the second brother in Figure 44, he now makes a slight but very sharp shift to his right (reinforced by gaze) in establishing a fresh and distinct chunk of space to refer to the third brother.

(17) baat5-ni0 phuu5 nò̀ng4 [phu0-nan4] la 0 mèènl pên3...phuu5 thiil $\mathrm{pcl}$ person noongt person-that $\mathrm{pcl}$ be be person rel keet5 lun4 lang3 khoòng3 khòj5 qiik5 baat5-ni0-na0 born series after of I more pcl

'Now. [that one $]_{\text {Fig } 45}$ who is (my) nóong4 is the one who ... the one who is born after me in addition:

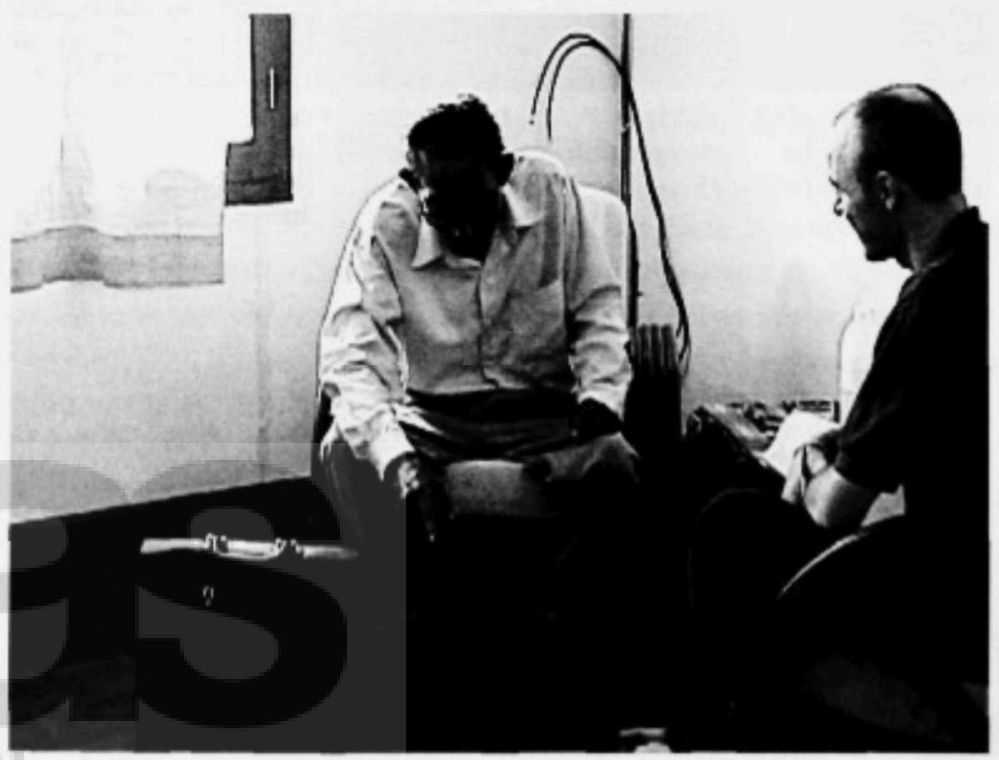

Figure 45 
This is followed by a comment on how he, as second brother, will address this third brother, and how the third brother will address him in return.

$$
\begin{aligned}
& \begin{array}{clllll}
\text { (18) baat5-ni0 } & \text { [khòòj5] } & \text { keet5 } & \text { kòònl } & \text { [phuu5-nan4] - } \\
\text { pcl } & \text { I } & \text { born } & \text { before } & \text { person-that } \\
\text { phuu5-nan4 } & \text { tòòng4 } & \text { qeen4 } & \text { khòòj5 } & \text { pên3 } & \text { qaaj4 qiik5 } \\
\text { person-that } & \text { must } & \text { call } & \text { I } & \text { be } & \text { qaaj4 more }
\end{array}
\end{aligned}
$$

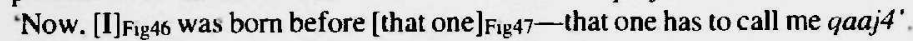

Here, Mr. Naak uses pronounced pointing gestures to single out the two referents, this time pointing to himself when referring to himself (Figure 46) and pointing to the newly established chunk of space, low and slightly to the right of center when referring to the third brother (pushing the chunk of space farther out in Figure 47 and differentiating it more clearly).
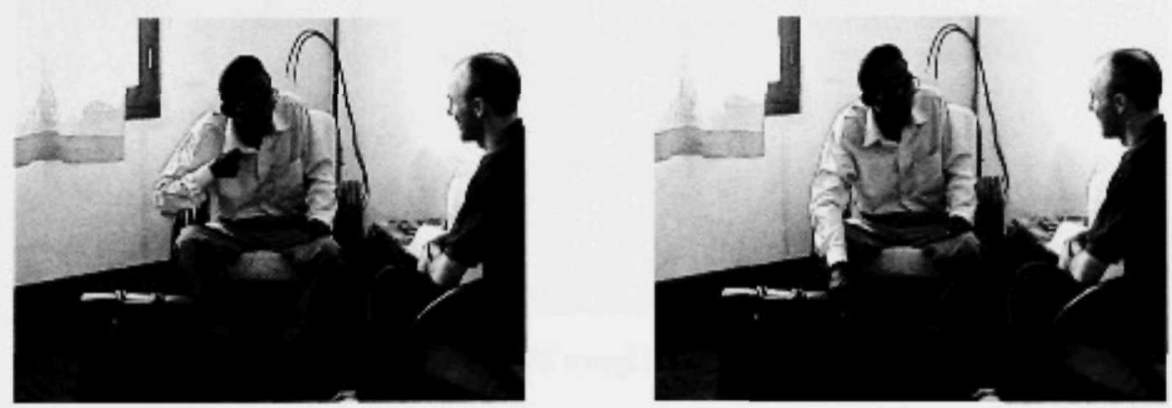

Figures 46 and 47

Here, as in so many examples we have seen so far, the timing of speech and gesture is closely coordinated. The speaker's mentions of different referents occur at the same time as the stroke of deictic gestures referring to the same referents.

Now Mr. Naak encounters a representational problem. He wants to explain that as a middle brother, he is nòng 4 'younger sibling' with respect to his older brother. yet qaaj4 'older brother' with respect to his younger brother. To make this point, he now wants to refer once again to the first brother, who was introduced as a discourse referent earlier in the sequence (see the lower white circle in Figure 41). The previous gestural reference to the first brother was a pointing gesture to the very low space directly in front of the speaker (Figure 40). This space was set up at a time when the spatial layout of the diagram was motivated by a simple mapping of the father-son relation onto a vertical line, with father above and son below (Figure 41). Since then. however, two things have happened. First, the chunk of space directly in front was on one occasion used to refer to the speaker himself as the second brother (Figure 44). Secondly, every other gestural reference to the speaker himself has been nuade by the speaker pointing to his own body, thus establishing his own body as the physical point of reference to himself as second brother. Thus, the speaker now physically represents himself in the diagram (i.e., he has brought himself-in-theinteraction and himself-in-the-diagram into alignment, in contrast to their earlier separation in Figures 43 and 44 ). Thus, the diagram at this moment looks like Figure 48 : 


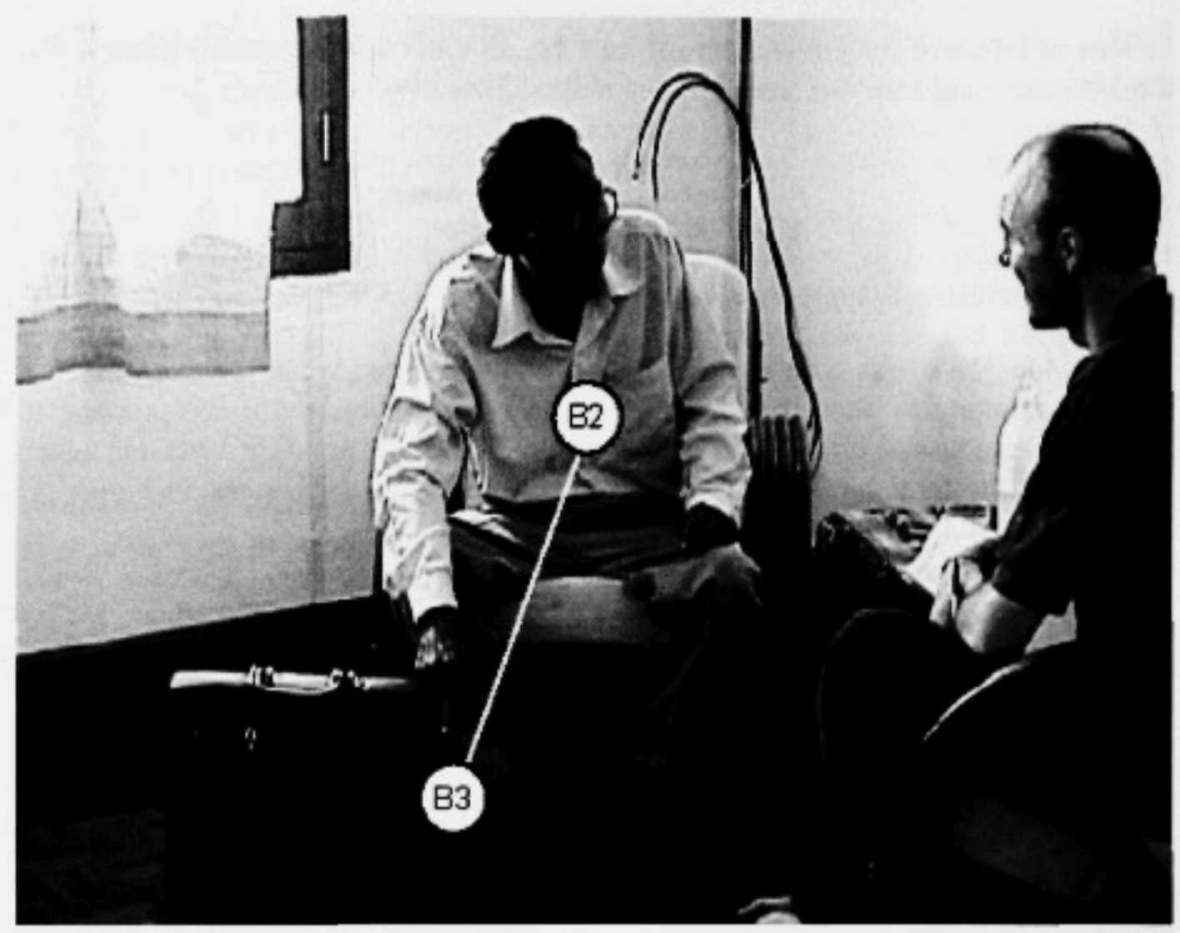

Figure 48

The semiotic motivation of the diagram is now to depict relations between ranked siblings. with the result that Mr. Naak needs the first brother (as B1) to be higher than himself, B2 (but not vertically above; cf. Figure 36 ). He is currently holding a right-hand index-finger pointing gesture at the chunk of space to his lower right (representing B3), and this gesture is held fast throughout his next series of gestures.

Mr. Naak's problem is to create a new chunk of space referring to his older brother, Bl, since the space he used before-in front and below-is no longer appropriate or available (having been deactivated due to the placement of a new point of reference in the same space; Figure 44). His solution is to annex space in the left extreme periphery of his gesture space (appropriately representing Bl's status as higher than but not directly above the other brothers). The four deictic gesture strokes depicted in Figures $49-52$ refer to B1. B1. B2 (i.e., the speaker hinswelf), and then B1, respectively.

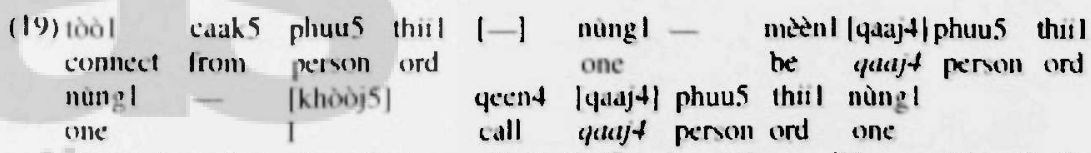

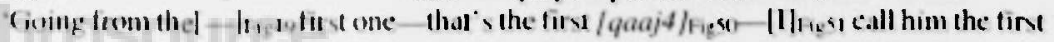
lqaajt/1ips: 

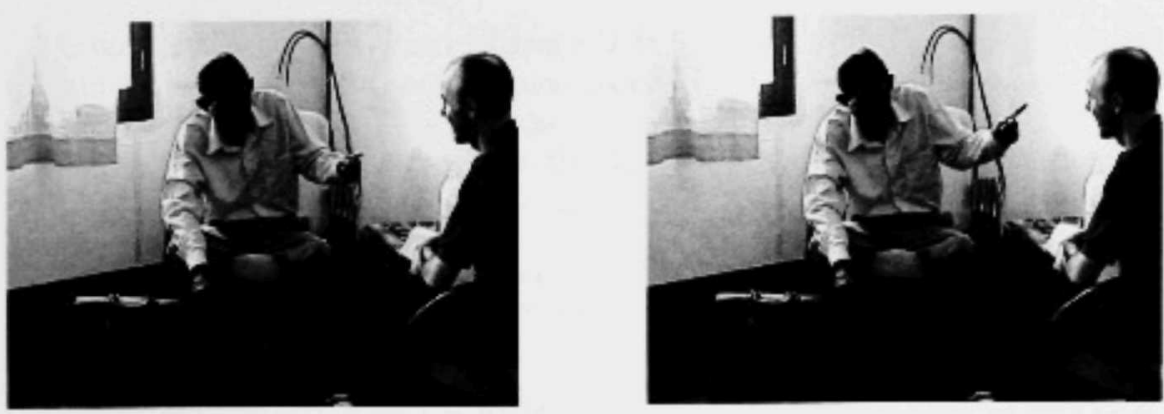

Figures 49 and 50
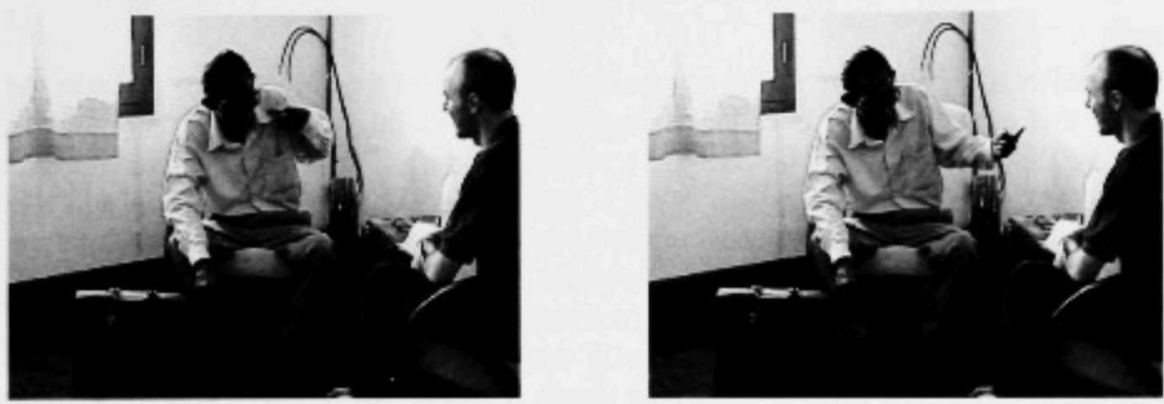

Figures 51 and 52

Figures 49-52 illustrate a hold-and-work-with-free-hand strategy (as used in Example 1), in which the moving hand represents something being asserted in the discourse (relating directly to what is being said), while the nonmoving hand forms a held deictic gesture anchored on a referent that was just active and will be retumed to, but that during this section of the discourse is backgrounded..$^{15}$

Having made this digression about his first brother, $\mathrm{Bl}$, establishing a whole new position for him in the diagram, Mr. Naak turns his attention now back to B3, the referent of the right-hand deictic gesture he set up in Figure 45 and has held in place for over 20 seconds throughout the sequence illustrated in Figures 47-52. By the time he begins to speak, his gaze is already back on B3's chunk of space, indicating that he is now foregrounding it as a referent. The deictic gestures, pointing to B3 and the speaker (as B2) respectively, are shown in Figures 53 and 54.

\footnotetext{
(20)[tòòl] caak5 khodj5 long2 paj3 qiik5 - [qeen4] qaajt connect from I descend go more call qaajt qeen4 khò̀j5 pên3 qaaj4 phuus thiil sò̀ng3 call 1 be qaaj4 person ord two '(The one) [connecting] Figs further down from me - [calls/Figs (me) qaajt calls me the second qaaj4.
} 

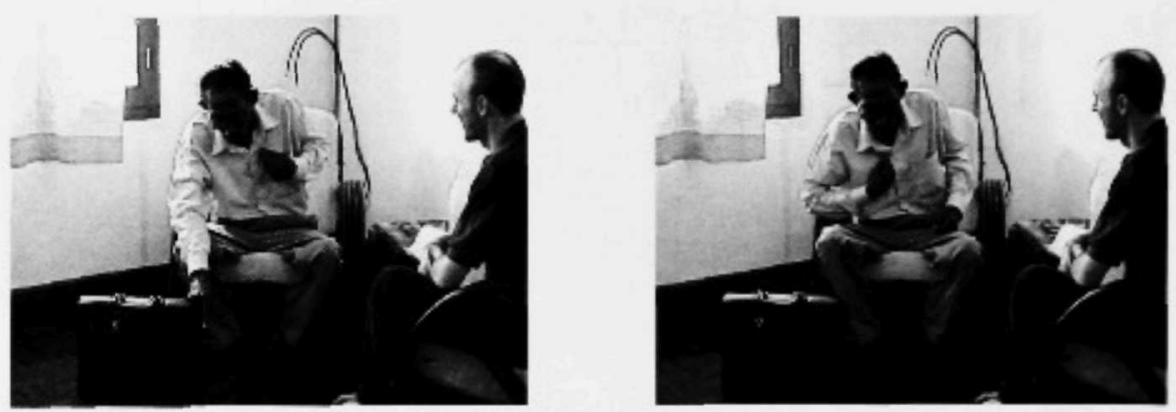

Figures 53 and 54

Finally, Mr. Naak introduces yet another younger brother in order to reiterate the point that a brother who is called nòng4 'younger sibling' by his elder sibling will still be called qaaj4 'older brother' by a younger sibling. This fourth brother is placed even farther to the right in Mr. Naak's developing diagram. In order to add this additional node, Mr. Naak uses a place-mark technique to maintain a distinction between the existing B3 node (held in place throughout Figures 47-52) and a new B4 node, farther out to the right. He first points with his right hand to the B3 node (Figure 55) and then points momentarily with his left hand to his own right-hand gesture (Figure 56). as if to hold that chunk of space down, thus giving the right hand freedom to move across and create a new and distinct chunk of space with a new and distinct referent:

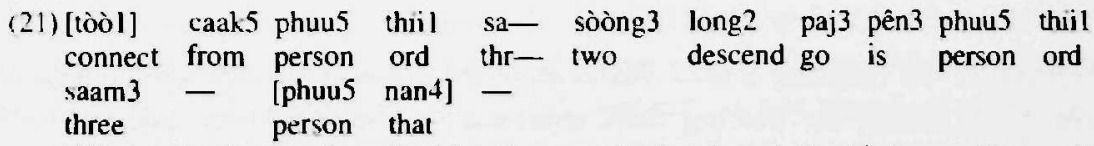

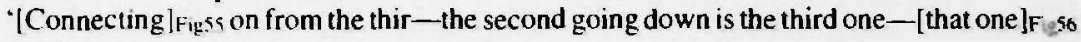
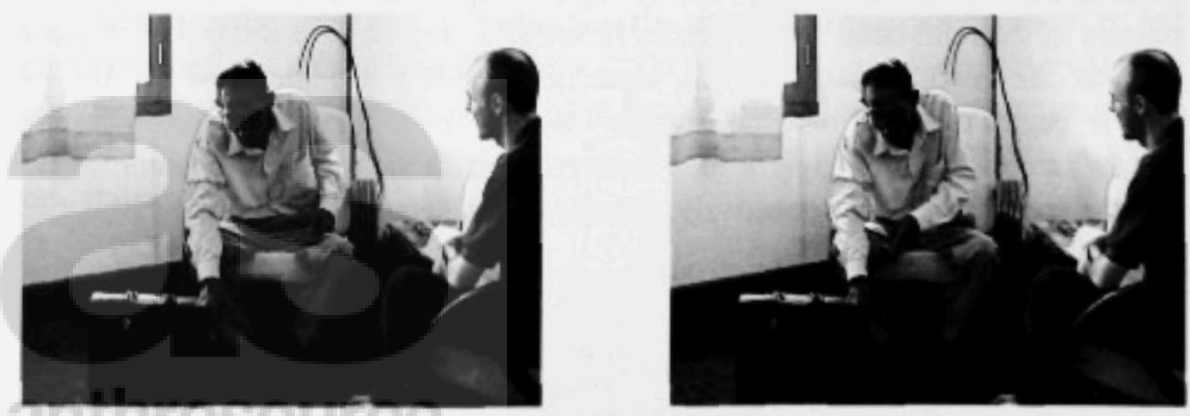
He now points to a new chunk of space in the low right periphery, creating a new node in the diagram for B4, then pointing once again to B3, as he explains the terms the two brothers will use for each other. Figures 57 and 58 show the preparation and stroke for the gesture referring to the fourth brother. Figures 59 and 60 show the same for the third brother. The speaker's gaze follows the deictic gestures.

$\begin{array}{llllllll}\text { (22) [la0] } & \text { [ñang2] } & \text { mii2 } & \text { nòòng4 } & \text { qiik5 } & \text { phuus } & \text { nùng1 qiik5 baat5-ni0 - } \\ \text { pcl } & \text { still } & \text { there.is } & \text { nòong4 } & \text { more } & \text { person one more pcl } \\ \text { [tòòng4] } & \text { [qeen4] } & \text { phuu5-nii4 } & \text { pén3 } & \text { qaaj4 phus thii saam3 } \\ \text { must } & \text { call } & \text { person-this } & \text { be } & \text { qaaj4 } & \text { person ord three }\end{array}$

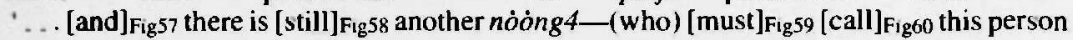
qaaj4, the third one'.
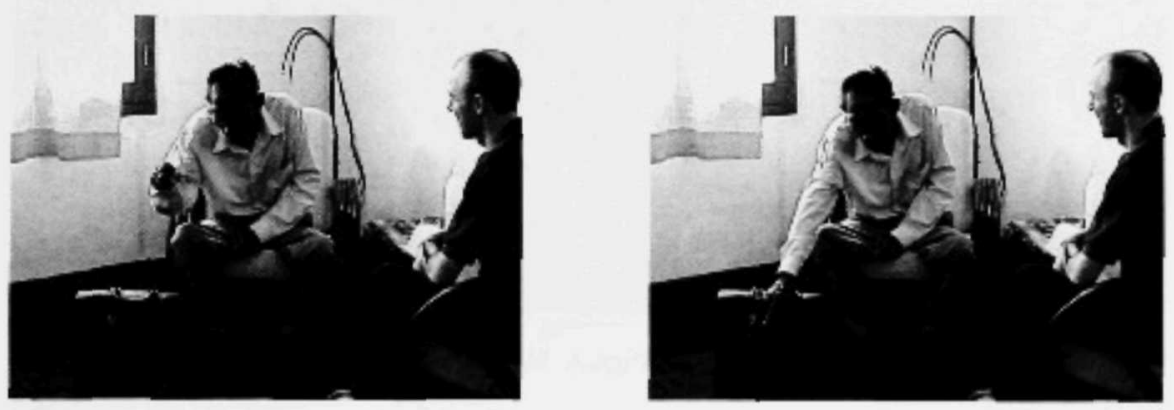

Figures 57 and 58
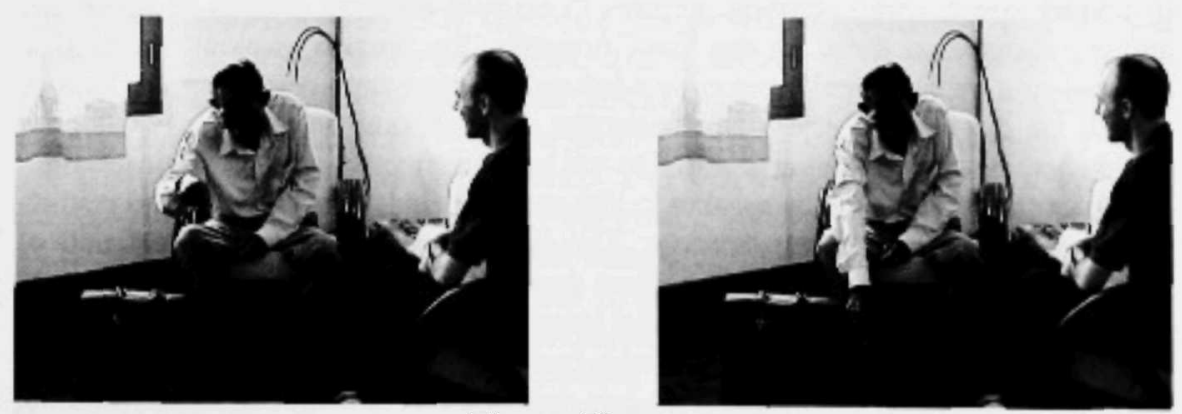

Figures 59 and 60

The preparation phases for these two pointing gestures (shown in Figures 57 and 59) are exaggerated (i.e., they are raised vertically higher than one might expect), presumably helping to accentuate the distinctness in the diagram between these two rather proximate chunks of space, referring to the third and fourth brothen.

The final state of the diagram is made explicit in Figure 61 (cf. Figure 36): 


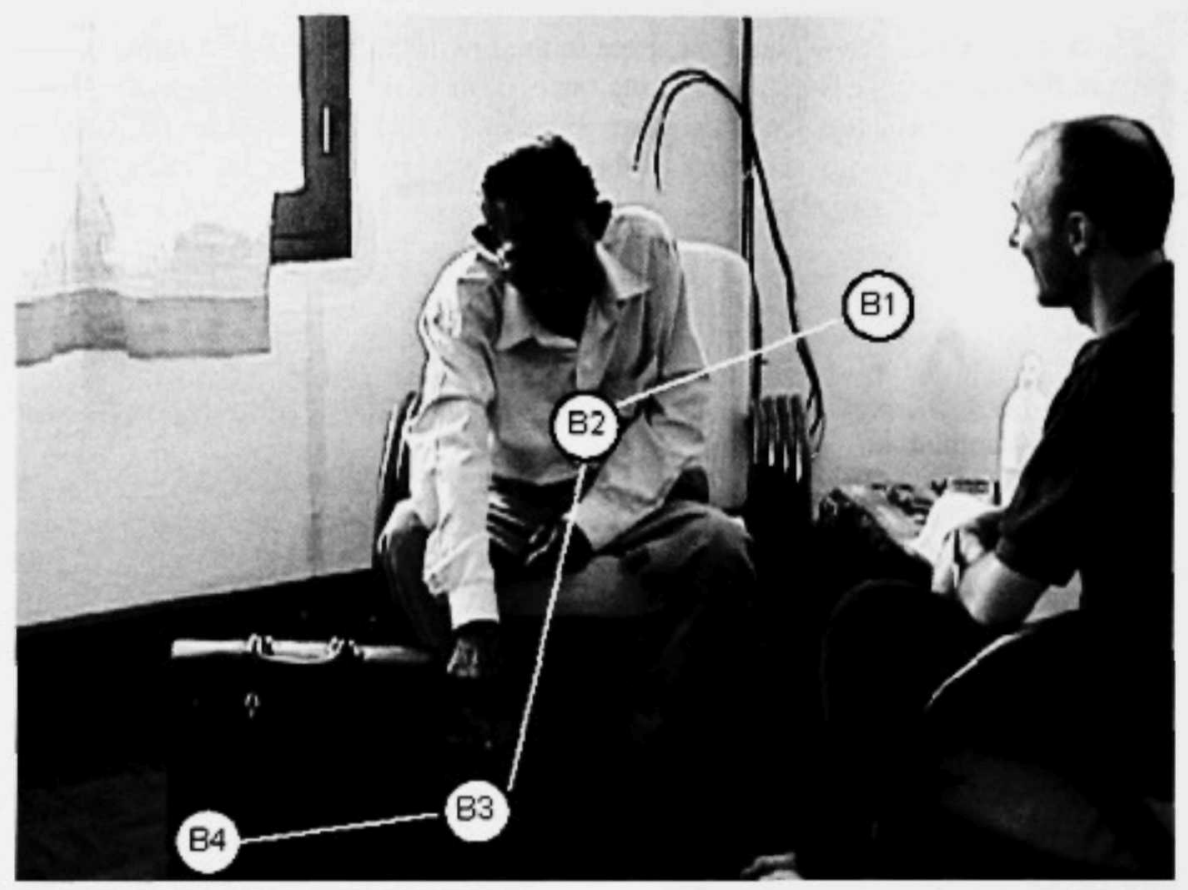

Figure 61

\section{Discussion of Example 2}

As in Example 1. the speaker in this example creates a complex virtual diagram in gesture space, using pointing gestures to activate different chunks of space and assign reference to them. In this case. however, the speaker exploits the vertical dimension in metaphorically mapping relational structure onto gesture space. Though virtual, the diagram displays spatial cohesion and temporal persistence. Points on it remain active while not being gestured to and become targets for later deictic gestures.

Also as in Example 1, the speaker in this example finds himself having to restructure or edit his diagram as it develops. This is due firstly to physical constraints of the gesture space, emergent as the diagram develops, and secondly to changing metaphorical mapping of the diagram's spatial structure to its intended meaning. Mr. Naak uses the techniques of hold-and-work-with-free-hand (Figures 49-53; cf. also Figures 16-20 in Example 1) and move-body-into-new-space (compare Figures 37 and 58; the distinction in this example is more subtle than in Example $1-c f$. Figures 19 and 20). Mr. Naak also adds a new editing technique, namely reassignment-of-old-chunkto-new-chunk. This refers to the case in which a certain chunk of space previously employed to stand for a certain referent is no longer usable for some reason (here the space is $t(x)$ crowded and the semiotic/metaphoric motivation for the placement of the chunk in question has changed), and the speaker simply creates another chunk with the same reference elsewhere in the gesture space (Figures 40,49, and 50). The referent of the gesture is not new but is currently semiactive, having already been established in the discourse. 


\section{Summary and Concluding Discussion}

\section{Summary}

Movements of the hands can be used to create structured arrangements of reference-activated chunks of space in otherwise undifferentiated gesture space. Such virtual diagrams, whose only real existence is in the minds of interlocutors, have temporal persistence and spatial cohesion, and accordingly they can be manipulated (e.g., shifted, resized, rotated) by movements of the hands. They are not literally manipulated, but effectively so, by manual semiotic devices such as virtual holding and mimetic enactment. Further attesting to their structural robustness, such diagrams may need to be overtly edited. Features of a gesture-created diagrammatic configuration can be altered while persistence and general cohesion of the diagram is maintained. The need for adjustment may be due to change in what is intended (i.e., errors, change of mind), unforeseen constraints of the gesture space, or changing semiotic motivation for the layout of the diagram (e.g., due to competing metaphors). The latter two motivations were observed in the data presented above.

Four techniques for editing were observed: (1) hold-and-drag, (2) hold-and-workwith-free-hand, (3) reassignment-of-old-chunk-to-new-chunk, and (4) move-bodyinto-new-space.

There are likely to be further means for editing or otherwise manipulating diagrams and models produced with co-speech gesture. This is a matter for further research.

\section{Gaze}

Throughout the discussion, I have repeatedly mentioned the involvement of speakers' gaze in the construction and maintenance of gesture diagrams. High sensitivity to the direction of others' gaze is a primordial feature of human perception and cognition (Baron-Cohen 1995:38 ff). Since gaze provides a directional vector, it can constitute a deictic gesture in itself (Enfield 2001:202-203). And it can be an especially powerful means to compound the attention-directing and focusing function of manual deictic gestures. Many of the mentions of gaze in the above sequences involve this kind of compounding of deictic function, in which two deictic vectors converge, one projected by the hand and one by the eyes.

The function of deictic gaze in constructing gesture diagrams may not only be to strengthen the referent-creating indexical power of a deictic hand gesture, but may also be to allow more accurate establishment of referential chunks in three-dimensional space. If a speaker simply hand-points into nearby space without looking, an addressee can imagine a vector being projected, but cannot know from form alone how far along that vector the intended referent is located. (When a referent is located at greater distances, people can employ angle of the pointing arm for signifying distance. Higher angle of a pointing arm is a conventional way of signifying that a referent is farther away.) However, if one simultaneously hand-points and casts one's gaze in a given direction, one exploits two vectors originating at different points on a vertical plane. The respective angles of these two vectors can be varied such that they will converge at different distances from the body. This allows an onlooker to determine how far away from a speaker a referential chunk of space-which is not physically differentiated from surrounding space and whose location, therefore, cannot 
be determined by direct perceptual evidence-is intended to be. An example of such manipulation of the angle of gaze can be seen in the later part of the first sequence described above, in which Mr. Phouthong maintains four separate referential chunks of space on a flat plane in front of his body. His use of different angles of gaze helps to provide the extra accuracy required for keeping these chunks distinct in what is becoming a crowded space. Compare Mr. Phouthong's downward gaze at his children in Figures 29 and 30 with his outward gaze to his grandchildren in Figure 11 and in Figures 27 and 28.

A further use of gaze in these sequences is to signal and direct attention to features of the diagram as relevant in the discourse. In Example 20, Mr. Naak resumes discussion of a referent, B3, that has been backgrounded momentarily, but visually held in play by a frozen index-finger deictic gesture. As he brings this referent back into the foreground of discourse with his speech, Mr. Naak simultaneously directs his gaze to the relevant node on the diagram (illustrated in Figure 53), signaling his renewed attention to it in the exposition.

\section{Further Work}

Relatively little is known about the production of diagrams using co-speech gesture, and we are clearly in need of further descriptive studies and more refined analyses. We need to know more about the techniques people employ, the kinds of structures people depict, ways of integrating gestural depictions with speech, and methods of editing and adjusting these interactively constructed images. Only with extensive descriptions from a range of cultures may we genuinely address more overarching questions concerning the systematicity, productivity, and universality of speakers' use of co-speech gesture in spontaneously spatializing both spatial and nonspatial concepts and locally manipulating the resulting representations.

In addition to broader cross-cultural data, we need a common vocabulary for referring to distinctions in form, meaning, and function of co-speech gestures. Many current distinctions are insightful yet lack a solid theoretical basis. There are at least three major problems with familiar categories such as beats, metaphoric gestures, and iconic gestures as they are currently used. First, these terms are not consistently defined. The same terms are used with different meanings by different researchers. Second, the bases for categorization are not consistent. Sometimes gestures are characterized on the basis of form (e.g., beats as biphasic), sometimes on the basis of domain of functional application (e.g., regulators as devices for managing discourse and interaction), sometimes on the basis of semiotic status (e.g., emblems as symbolic and conventional-arbitrary). Often these dimensions are conflated or some combination of them is implied. The third problem is the suggestion that a given gesture will exemplify just one of these types. Often we are unable to say which category a gesture belongs to. I argue that this is because gestures are not unanalyzable units but complex signifying actions that can and must be characterized by features on a number of (to some degree independent) dimensions. These include (1) formal properties, (2) functional contribution to the utterance in which the gesture appears, and (3) semiotic structure (cf. Figure 4). The details of categorization of gestures within formal, functional, and semiotic dimensions are yet to be worked out. 


\section{Concluding Remarks: Spoken Language as Speech-with-Gesture}

Speakers do not merely speak. They routinely integrate speech with other semiotic forms, most of these in the visual modality, and in many cases the nonspeech component of their communicative behavior becomes an indispensable part of the overall message (Clark 1996; Engle 1998; Goodwin 2000; Kendon 1972, 2000; Slama-Cazacu 1976; inter alia). But scholars of spoken language have traditionally concentrated on speech alone, using the written representation in particular to abstract speech away not only from its prosodically rich and expressive phonetic form, but from the abundant visual richness of the speech context. In the vast majority of contexts in which language is used, speech is merely part of the full array of semiotic resources people systematically draw on to convey information to and derive information from each other. However, in linguistics, the methodological isolability of the auditory mode of speech has resulted in the routine factoring out from the object of study of everything but an abstracted form of speech. Mainstream linguistic science has developed a corporate blindness to speakers' nonspeech semiotic behavior. For some domains of investigation this may be unproblematic, but for others it is disastrous.

The two examples described in this article show speakers creating composite signals, speaking while depicting highly structured representations using their hands in visual space (Clark 1996; Engle 1998). Composite signaling is commonplace in the dominant and most natural setting for language production and comprehension, namely face-to-face interaction in which interlocutors share the same physical space and can hear and see each other. Speech is just one aspect of something semiotically broader and psychologically more fundamental (Clark 1996; Goodwin 2000; Kendon 1972; McNeill 1985).

It is instructive to consider these comments about spoken language in the context of language more generally, by comparing the kind of data described above with what is known about sign language, a form of language in which only the visual modality is employed. Emmorey (2001:166) shows that signers of American Sign Language can employ manual spatialization of nonspatial abstract schemas to "facilitate comprehension" of those schemas, just as any sighted person can do by making use of ink-on-paper diagrams. That is, by creating diagrams manually, signers can take advantage of the beneficial effects on comprehension and memory of visually spatializing nonvisuospatial ideas (Glenberg and Langston 1992). But speakers of spoken languages do this too, as the present study shows. And I do not consider the data discussed in this article to be at all unusual.

By comparing sign language to spoken language alone we factor out the reality of speakers' extensive reliance on the manual/visual modality in conveying spatial and other information. This may lead us to conclude-wrongly, I argue - that it is a unique property of signed languages that "space itself is used to express spatial relationships" (Emmorey 2001:152). It is true that spoken language does not use space to express spatial relationships, but when speakers express spatial relationships, they seldom rely on speech alone. Speakers of spoken languages normally have the option of using manual semiotics-the same modality as sign language-to express spatial information, not only in iconically depicting physical objects and spatial layouts, but also in spatializing complex nonspatial concepts, such as kinship relations, in diagrammatic fashion. Further research will tell us 
how systematic and conventional such functions of co-speech gesture are, and we will then be able to compare the results with what we know about sign language. But the facts will never be discovered if we insist on restricting our scope to spoken language. Instead, we must ask what speakers do when they communicate in faceto-face interaction. This makes speech-with-gesture our legitimate unit of analysis, not speech alone.

\section{Notes}

Acknowledgments. I gratefully acknowledge financial support for this research provided by the Max Planck Society and expert technical support from the Technical Group of the Max Planck Institute for Psycholinguistics, Nijmegen. I am grateful to Alex Dukers for his help in preparing the illustrations. For discussion during development of this work, I thank fellow members of the Gesture Group at the MPI Nijmegen (Marianne Gullberg, Sotaro Kita, Hedda Lausberg, Alissa Melinger, and Mandana Seyfeddinipur), members of the audience at a session of the First Congress for the International Society for Gesture Studies (Austin, Texas, June 2002), and members of the audience at a Linguistics Department seminar at the University of Melbourne. I also thank in particular Nick Evans, Chuck Goodwin, John Haviland, Adam Kendon, Sotaro Kita, Steve Levinson, Pamela Perniss, Eve Sweetser, David Wilkins, and two anonymous referees for helpful comments and discussion. Finally, I would especially like to thank my friends Mr. Naak and Mr. Phouthong for generously allowing me to video the interviews and publicize the results.

1. Lao is a southwestern Tai language spoken in Laos, Thailand, and Northeast Cambodia (Enfield 1999).

2. An anonymous reviewer points out that although words are also evanescent, their referents persist and can be pointed to by anaphors. But the difference here is that a verbal anaphor like it is not a real index, in that its form is not causally determined by contingent facts about its referent. It takes the phonological form /it/, regardless of the position of the referent. But when one index-finger-points to a referent, the directional orientation of the gesture varies analogically and is "dynamically connected" to some physical counterpart of its referent (Peirce 1965:171). In the case of the pronoun, the physical form of the signifier is not "really affected by" what it signifies (Peirce 1965:143).

3 . Many of the semiotic generalizations to be made here apply equally to co-speech gesture and to manual signs in sign language. Indeed, I borrow from the insights of previous research on sign language, beginning with Mandel's (1977) taxonomy of iconic and other devices in American Sign Language (cf. also Kendon 1988; Taub 2001; inter alia).

4. The base concept of a beard is not actually directly represented in the first instance. The hand is not iconic of a beard, but rather of a hand stroking a beard.

5. Mandel (1977) focused on American Sign Language, and Kendon (1988) on auxiliary sign languages of Aboriginal Australia. Clearly these systems are more structured, conventionalized, and grammaticalized than what we normally refer to as co-speech gesture. Even so, most manual signs and co-speech gestures can be considered together in terms of the semiotic devices they use. There is, of course, an added dimension of grammaticalization in sign language not clearly attested in co-speech gesture. As one would expect, much of this involves a greater level of arbitrariness (e.g., in formalstructural constraints) than the iconic/indexical devices of co-speech gestures discussed in this article (cf. Emmorey 2002. inter alia).

6. I make more distinctions within the category of deictic gestures than the authors mentioned here. The distinctions noted in Figure 4 draw on findings of recent research on pointing (Haviland 1993; Kita 2003; inter alia), especially Liddell 2000 and Clark 2003. The category of placing is due to Clark 2003. 
7. It is common for pointing gestures to have deferred reference (Quine 1971), as when one points to an empty chair (the base) when referring to John (the referent), who was just sitting in the chair. Such cases demonstrate that pointing is not semiotically "primitive" or "primordial," as is sometimes suggested (cf. Haviland 1993; Kita 2003; Wittgenstein 1953).

8. The content of these representations is of significant interest from a number of different perspectives. The interviews from which the data are taken are rich in both verbal and gestural metaphor, depicting many aspects of the Lao kinship system and terminology. These issues are the subject of ongoing research, but go beyond the scope of this article. Here I concentrate on techniques for abstract diagramming using co-speech gesture, in which kinship happens to be the domain of discourse in the two examples.

9. The diagrammatic representation of kinship cross-culturally is not well described and would be a fruitful field for further research.

10. Conventions of kinship diagrams: Triangles represent males, circles females; the equals sign refers to the marriage relationship; horizontal lines refer to sibling relationship; vertical lines refer to the parent-child relationship.

11. Unless otherwise specified, square brackets in the example sentences indicate the point of occurrence of the gesture stroke (i.e., the phase in which "the meaning of the gesture is expressed"; McNeill 1992:83). Each such stroke is depicted in one of the illustrations supplied with each example sentence, supplied in the order in which they occur. In deictic gestures, unlike most types of representational gesture, the phase in which "the meaning of the gesture is expressed" does not align with "the peak of effort in the gesture" (pace McNeill 1992:83; I am indebted to Jan Peter de Ruiter for making this point clear to me). The transliteration of Lao used here follows IPA standard except for the following: $e=$ schwa; $\hat{e}=$ highmid front vowel; $\grave{e}=$ low front vowel; $\grave{o}=$ low back vowel; $\grave{u}=$ high back unrounded vowel; $\boldsymbol{n g}=\operatorname{velar}$ nasal; $\tilde{\boldsymbol{n}}=$ palatal nasal; $\boldsymbol{q}=$ glottal stop. Lexical tone is indicated by numeral, as follows: 0 = unstressed, atonal; 1 = mid level (33); 2 = high rising (35); 3 = low rising (13); 4 = high falling (51); $5=$ low falling (31). Interlinear glosses are as follows: $1 / 2 / 3$ (1st/2nd/3rd person); irr (irrealis); pcl (particle); pl (plural); rel (relativizer); rdp (reduplication); rcp (reciprocal); neg (negative); comp (complementizer); tpc (topic); and ord (ordinator). A dash (-) indicates a pause.

12. Video clips from which the stills referred to in this article were created may be viewed at the journal website.

13. This is how reference-activated chunks of space can be set at particular distances away from the body, which would be impossible with only a single vector. It also shows how a token space can be set up outside the gesture space (pace Liddell 1995:33).

14. Due to space restrictions, some hand movements in this sequence and in Example 7 and Figures 23 and 24 are omitted from the discussion. These gestures formally resemble deictic gestures but do not reference-activate chunks of space. They are likely to be beats, opportunistically superimposed on deictic gesture forms.

15. This use of held gesture is a means of keeping a temporarily backgrounded element of the discourse visually accessible, something that speech alone cannot do because of its linear modality. Emmorey states that "the ability to visually perceive a backgrounded element while processing focussed information within a discourse" is an aspect of language processing that is "modality specific" to signed languages (2002:147), implying that spoken languages afford no such ability. This is only true if we consider spoken language as involving speech alone. But spoken language is usually accompanied by gesture, and the present example shows that speakers of spoken languages also exploit this ability. (See Emmorey et al. 2000: 173 for another example in which a speaker is able via co-speech gesture to maintain a backgrounded element in the visual field.) 


\section{References Cited}

Baron-Cohen, Simon

1995 Mindblindness: An Essay on Autism and Theory of Mind. Cambridge, MA: MTT Press.

Clark, Herbert H.

2003 Pointing and Placing. In Pointing: Where Language, Culture, and Cognition Meet.

Sotaro Kita, ed. Pp. 243-268. Mahwah, NJ: Lawrence Erlbaum Associates.

Efron, David

1972[1941] Gesture, Race, and Culture. The Hague: Mouton.

Ekman, Paul, and Wallace V. Friesen

1969 The Repertoire of Nonverbal Behavior: Categories, Origins, Usage, and Coding.

Semiotica 1:49-98.

Emmorey, Karen

2001 Space on Hand: The Exploitation of Signing Space to Illustrate Abstract Thought.

In Spatial Schemas and Abstract Thought. Merideth Gattis, ed. Pp. 147-174. Cambridge, MA: MIT Press.

2002 Language, Cognition and the Brain: Insights from Sign Language Research.

Mahwah, NJ: Lawrence Erlbaum Associates.

Emmorey, Karen, Barbara Tversky, and Holly A. Taylor

2000 Using Space to Describe Space: Perspective in Speech, Sign, and Gesture. Spatial Cognition and Computation 2(3):157-180.

Enfield, N. J.

1999 Lao as a National Language. In Laos: Culture and Society. Grant Evans, ed. Pp. 258-290. Chiang Mai: Silkworm Books.

2001 "Lip-Pointing"-A Discussion of Form and Function with Reference to Data from Laos. Gesture 1(2):185-212.

2003 Demonstratives in Space and Interaction: Data from Lao Speakers and Implications for Semantic Analysis. Language 79(1):1-36.

Engle, Randi A.

1998 Not Channels but Composite Signals: Speech, Gesture, Diagrams and Object Demonstrations are Integrated in Multimodal Explanations. In Proceedings of the Twentieth Annual Conference of the Cognitive Science Society. Mortan Ann Gernsbacher and Sharon J. Derry, eds. Pp. 321-327. Mahwah, NJ: Lawrence Erlbaum Associates.

Glenberg, Arthur M., and William E. Langston

1992 Comprehension of Illustrated Text: Pictures Help to Build Mental Models. Journal of Memory and Language 31(2):129-151.

Goffman, Erving

1963 Behavior in Public Places: Notes on the Social Organization of Gatherings. New York: The Free Press.

Goodwin, Charles

2000 Action and Embodiment within Situated Human Interaction. Journal of Pragmatics 32(10):1489-1522.

2003 Pointing as Situated Practice. In Pointing: Where Language, Culture, and Cognition Meet. Sotaro Kita. ed. Pp. 217-241. Mahwah، NJ: Lawrence Erlbaum Associates.

Haviland, John

-1993 Anchoring, Iconicity, and Orientation in Guugu Yimithirr Pointing Gestures. Journal of Linguistic Anthropology 3(1):3-45. 
2000 Pointing, Gesture Spaces, and Mental Maps. In Language and Gesture. David McNeill, ed. Pp. 13-46. Cambridge: Cambridge University Press.

Kendon, Adam

1972 Some Relationships between Body Motion and Speech: An Analysis of an Example. In Studies in Dyadic Communication. Aron Wolfe Siegman and Benjamin Pope, eds. Pp. 177-2 10. New York: Pergamon Press.

1977 Studies in the Behavior of Social Interaction. Bloomington: Indiana University.

1980 Gesticulation and Speech: Two Aspects of the Process of Utterance. In The Relationship of Verbal and Nonverbal Communication. Mary Ritchie Key, ed. Pp. 207-227. The Hague: Mouton.

1986 Some Reasons for Studying Gesture. Semiotica 62(1-2):3-28.

1988 Sign Languages of Aboriginal Australia: Cultural, Semiotic and Communicative Perspectives. Cambridge: Cambridge University Press.

Kita, Sotaro, ed.

2003 Pointing: Where Language, Cognition, and Culture Meet. Mahwah, NJ: Lawrence Erlbaum Associates.

Liddell, Scott

1995 Real, Surrogate, and Token Space: Grammatical Cconsequences in ASL. In Language, Gesture, and Space. Karen Emmorey and Judy S. Reilly, eds. Pp. 19-41. Mahwah, NJ: Lawrence Erlbaum Associates.

1998 Grounded Blends, Gestures, and Conceptual Shifts. Cognitive Linguistics 9(3):283-314.

2000 Indicating Verbs and Pronouns: Pointing Away from Agreement. In The Signs of Language Revisited: An Anthology to Honor Ursula Bellugi and Edward Klima. Harlan Lane and Karen Emmorey, eds. Pp. 303-320. Mahwah, NJ: Lawrence Erlbaum Associates. Mandel, Mark A.

1977 Iconic Devices in American Sign Language. In On the Other Hand: New Perspectives on American Sign Language. Lynn A. Friedman, ed. Pp. 57-107. New York: Academic Press.

McNeill, David

1985 So You Think Gestures Are Nonverbal? Psychological Review 92:350-371.

1992 Hand and Mind: What Gestures Reveal about Thought. Chicago: University of Chicago Press.

McNeill, David, ed.

2000 Language and Gesture. Cambridge: Cambridge University Press.

McNeill, David, Justine Cassell, and Elena T. Levy

-1993 Abstract Deixis. Semiotica 95(1-2):5-19.

Müller, Cornelia

1998 Iconicity and Gesture. In Oralité et gestualité: Communication multimodale, interaction. (Orality and gestuality: Multimodal communication, interaction.) Serge Santi, Isabelle Guaittella, Christian Cavé, and Gabrielle Konopczynski, eds. Pp. 321-328. Paris: L'Harmattan.

Peirce, Charles S.

1965[1932] Speculative Grammar. In Collected Papers of Charles Sanders Peirce, vol. 2, Elements of Logic. Charles Hartshorne and Paul Weiss, eds. Pp. 127-269. Cambridge, MA: Belknap Press of Harvard University Press.

Quine, W. V.O.

1971 The Inscrutability of Reference. In Semantics: An Interdisciplinary Reader in Philosophy, Linguistics, and Psychology. Danny D. Steinberg and Leon A. Jakobovits, eds. Pp. 142-154. Cambridge: Cambridge University Press. 
Scheflen, Albert E., with Norman Ashcraft

1976 Human Territories: How We Behave in Space-Time. Englewood Cliffs, NJ: Prentice-Hall.

Slama-Cazacu, Tatiana

1976 Nonverbal Components in Message Sequence: "Mixed Syntax". In Language and Man: Anthropological Issues. William C. McCormack and Stephen A. Wurm, eds. Pp. 217-227. The Hague: Mouton.

Taub, Sarah F.

2001 Language in the Body: Iconicity and Metaphor in American Sign Language. Cambridge: Cambridge University Press.

Wittgenstein, Ludwig

1953 Philosophical Investigations. Oxford: Basil Blackwell.

Language and Cognition Group

Max Planck Institute for Psycholinguistics

PB310

6500 AH Nijmegen

The Netherlands

Nick.Enfield@mpi.nl 